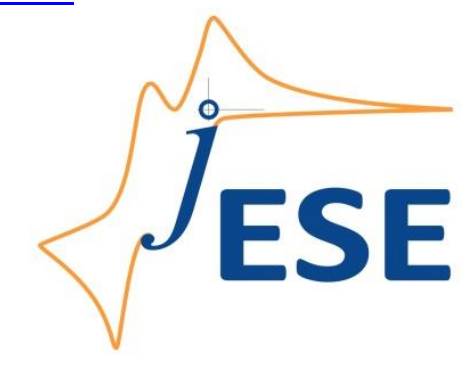

Open Access : : ISSN 1847-9286

www.jESE-online.org

Original scientific paper

\title{
Development of highly stable conductive multiwalled carbon nanotube ink using covalent and non-covalent functionalization for electrochemical sensors
}

\author{
Ana Elisa Ferreira Oliveira ${ }^{1}$, Arnaldo César Pereira ${ }^{1, \square}$ and Lucas Franco Ferreira ${ }^{2}$ \\ ${ }^{1}$ Departamento de Ciências Naturais, Universidade Federal de São João del-Rei (UFSJ), Praça Dom \\ Helvécio 74, Fábricas CEP 36301-160, Brazil \\ ${ }^{2}$ Laboratório de Eletroquímica e Nanotecnologia Aplicada, Universidade Federal dos Vales do \\ Jequitinhonha e Mucuri, MGT 367, Km 583, Alto da Jacuba, Diamantina, MG 39100-000, Brazil \\ Corresponding author: ${ }^{\boxplus}$ arnaldocsp@yahoo.com.br
}

Received: October 8, 2021; Accepted: November 19, 2021; Published: December 2, 2021

\begin{abstract}
The purpose of this work was the fabrication of a conductive carbon nanotube (CNT) ink. The proposed CNT ink remained remarkably stable over several months. The method includes combining the covalent and non-covalent functionalization, resulting in ink that exhibits excellent storage stability. The covalent functionalization was performed in the acid medium using $\mathrm{H}_{2} \mathrm{SO}_{4}$ and $\mathrm{HNO}_{3}$, while the non-covalent functionalization used sodium dodecyl sulfate (SDS) and ultrasonication. The materials were characterized by Fourier transform infrared spectroscopy (FTIR), scanning electron microscopy (SEM), electrochemical impedance spectroscopy (EIS), and cyclic voltammetry (CV). FTIR and SEM confirmed that at the non-covalent functionalization, SDS was successfully adsorbed on the $f$-CNT surface, while at the covalent functionalization, the functional groups (-COOH, $\mathrm{C}=\mathrm{O}$ and $-\mathrm{OH}$ ) were inserted into the CNT surface. Voltammetry and EIS indicated that SDS in the presence of functional groups facilitates electron transfer by improved electrical conductivity. The final product was a well-dispersed CNT ink with an average ohmic resistance of $18.62 \mathrm{k} \Omega$. This indicates that CNT ink can be used in the fabrication of electrochemical sensors.
\end{abstract}

Keywords

Carbon materials; printed sensors; conductive ink; electroanalysis; characterization

\section{Introduction}

The carbon nanotube (CNT) was first discovered by lijima in 1991 [1]. He was studying the synthesis of fullerenes using the arc discharge technique when a "new type of finite carbon structure consisting of needle-like tubes" was discovered. CNTs are good conductors of electricity, so they can 
be used to fabricate conductive inks. However, it is very hard to prepare good dispersions with CNTs, because CNTs tend to agglomerate uncontrollably and are usually found in the form of bundles due to van der Waals attractions. Weak dispersibility and insolubility of CNTs in solvents can limit their application [1-3].

In order to obtain homogeneous dispersions, several alternatives are being used to disperse CNTs, including mechanical and chemical methods. There are studies published using surfactants to improve the dispersions, such as sodium dodecylbenzene sulfonate (SDBS), sodium dodecyl sulfate (SDS), lithium dodecyl sulfate (LDS), sodium carboxymethyl cellulose (SCMC), polyvinylpyrrolidone (PVP) and others. Covalent functionalization is also used to change the dispersibility properties by adding functional groups to the CNT surface. To separate CNTs, mechanical methods such as ultrasonication and agitation can be applied [4-14].

In this work, the carbon nanotube ink was fabricated using functionalization. The functionalization of CNTs consists of attachments of organic or inorganic moieties to their structure. The objective is to improve the wetting, dispersion or adhesion characteristics since their application has been limited due to poor interactions [15]. The approaches available to modify the CNTs surface can be divided into covalent and non-covalent functionalization.

The covalent functionalization is based on the formation of covalent bonds between functional groups and the CNT surface. The non-covalent functionalization involves the wrapping or adsorption of molecules on the tubular surface of CNT. It is based on hydrogen bonds, van der Waals forces, electrostatic forces, $\pi-\pi$ stacking interactions, and others. Therefore, the non-covalent functionalization introduces fewer defects in the CNT structure, preserving the extended $\pi$-network of the tubes $[16,17]$. The aim of this work was to obtain a well-dispersive and cheap conductive ink with great long-term stability. The article explains didactic step-by-step of the fabrication, showing photos and schemes of the process and including a well-explained characterization study.

\section{Experimental}

\section{Reagents}

All reagents used were of analytical purity. SDS was obtained from Sigma-Aldrich (Brazil); $\mathrm{HNO}_{3}$, $\mathrm{Na}_{2} \mathrm{HPO}_{4} \cdot 7 \mathrm{H}_{2} \mathrm{O}$ and $\mathrm{NaH}_{2} \mathrm{PO}_{4}$ from Synth (Brazil). $\mathrm{H}_{2} \mathrm{SO}_{4}$ was purchased from Neon (Brazil). The MWCNT (purity $99 \%$, 6-13 nm diameter, 3.5-20 $\mu$ m length) were acquired from Nanocyl (Brazil). Photo Paper Matte A4 $108 \mathrm{~g}$ from Spiral (Brazil). All solutions were prepared with water by the Millipore Milli-Q system.

\section{Covalent functionalization of CNT}

To achieve a carbon nanotube (CNT) ink with great long-term stability, the CNT was functionalized by covalent and non-covalent means. The methodology for the covalent functionalization was developed based on previous works published [18-21]. The functionalized carbon nanotube (f-CNT) was produced from a multi-walled carbon nanotube (MWCNT) and a mixture of $\mathrm{H}_{2} \mathrm{SO}_{4} / \mathrm{HNO}_{3}(3: 1)$. A schematic illustrating the steps involved is shown in Figure 1.

In this method, $0.5 \mathrm{~g}$ of MWCNT, $62.5 \mathrm{~mL}$ of $\mathrm{HNO}_{3}$ and $187.5 \mathrm{~L} \mathrm{H}_{2} \mathrm{SO}_{4}$ were placed into a $500 \mathrm{~mL}$ flask. The mixture was sonicated for 2 hours and then left to rest for 20 hours. Next, the mixture was added carefully into a flask containing $500 \mathrm{ml}$ of deionized $\mathrm{H}_{2} \mathrm{O}$ and left decant for 2 hours. Finally, the suspension was repeatedly washed with $\mathrm{H}_{2} \mathrm{O}$ in centrifugation (4000 rpm) to purify the material. This process was repeated 10 times. Then the material was vacuum filtrated and dried at $110^{\circ} \mathrm{C}$ for 3 hours. The final product was a black powder called f-CNT. 


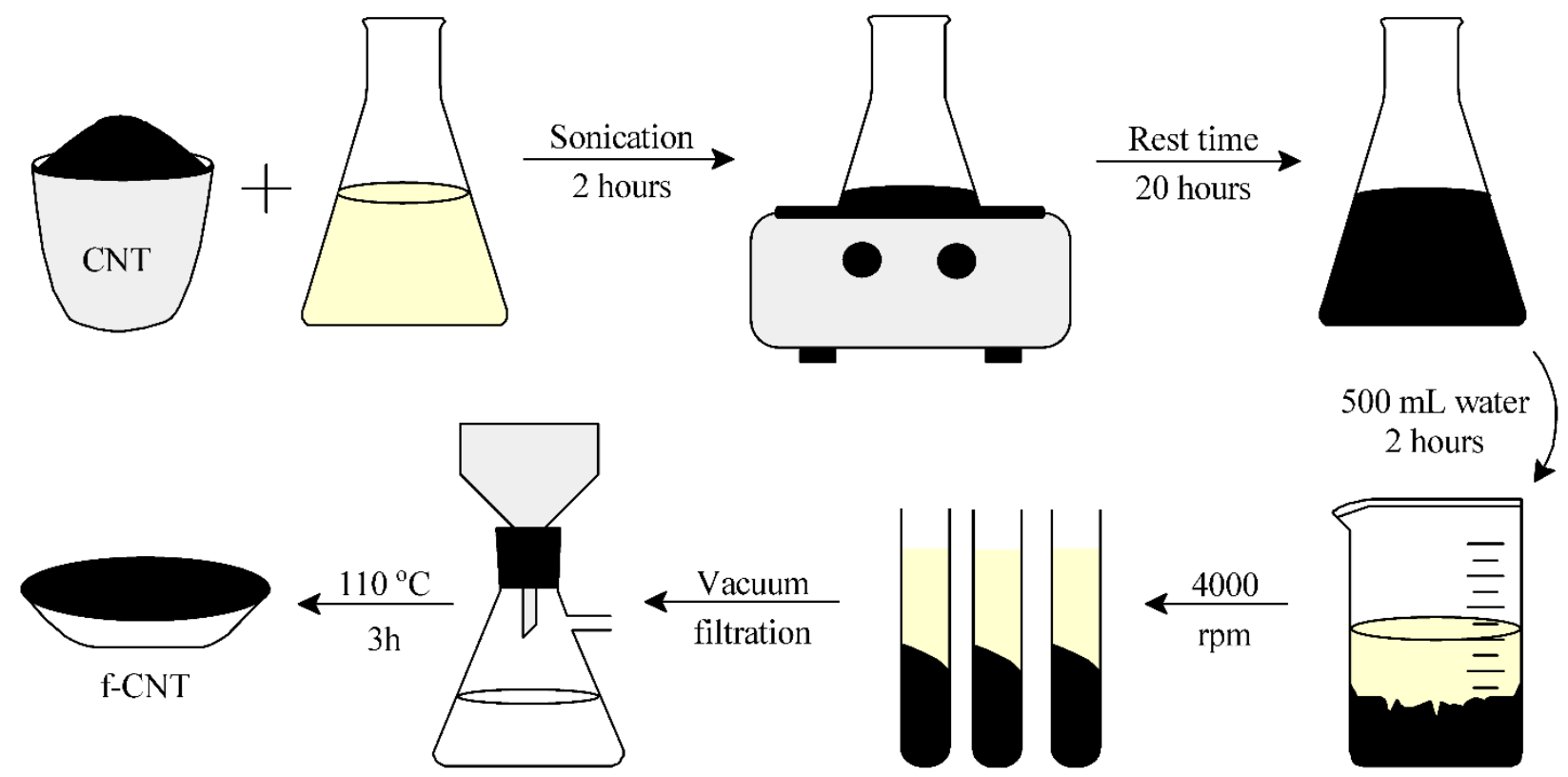

Figure 1. Representation of steps involved in the synthesis of f-CNT with $\mathrm{H}_{2} \mathrm{SO}_{4} / \mathrm{HNO}_{3}$

\section{Non-covalent functionalization of CNT}

The final step to synthesize the CNT ink was non-covalent functionalization. For that, an aqueous solution containing $8.0 \mathrm{mg} \mathrm{mL}^{-1}$ of sodium dodecyl sulfate (SDS) was prepared and sonicated for 15 minutes. Then, $\mathrm{f}-\mathrm{CNT}\left(8.0 \mathrm{mg} \mathrm{mL}^{-1}\right)$ was added to the solution and sonicated for 15 hours. The SDS and f-CNT concentrations were previously optimized. After sonication, the dispersion was centrifuged at $4000 \mathrm{rpm}$ for 30 minutes to remove undispersed CNT and the supernatant was recovered using a dropper. Finally, the resulting solution was vacuum filtrated to guarantee a welldispersive medium. The final product was the CNT ink (f-NCT/SDS). Figure 2 shows the steps of noncovalent functionalization.

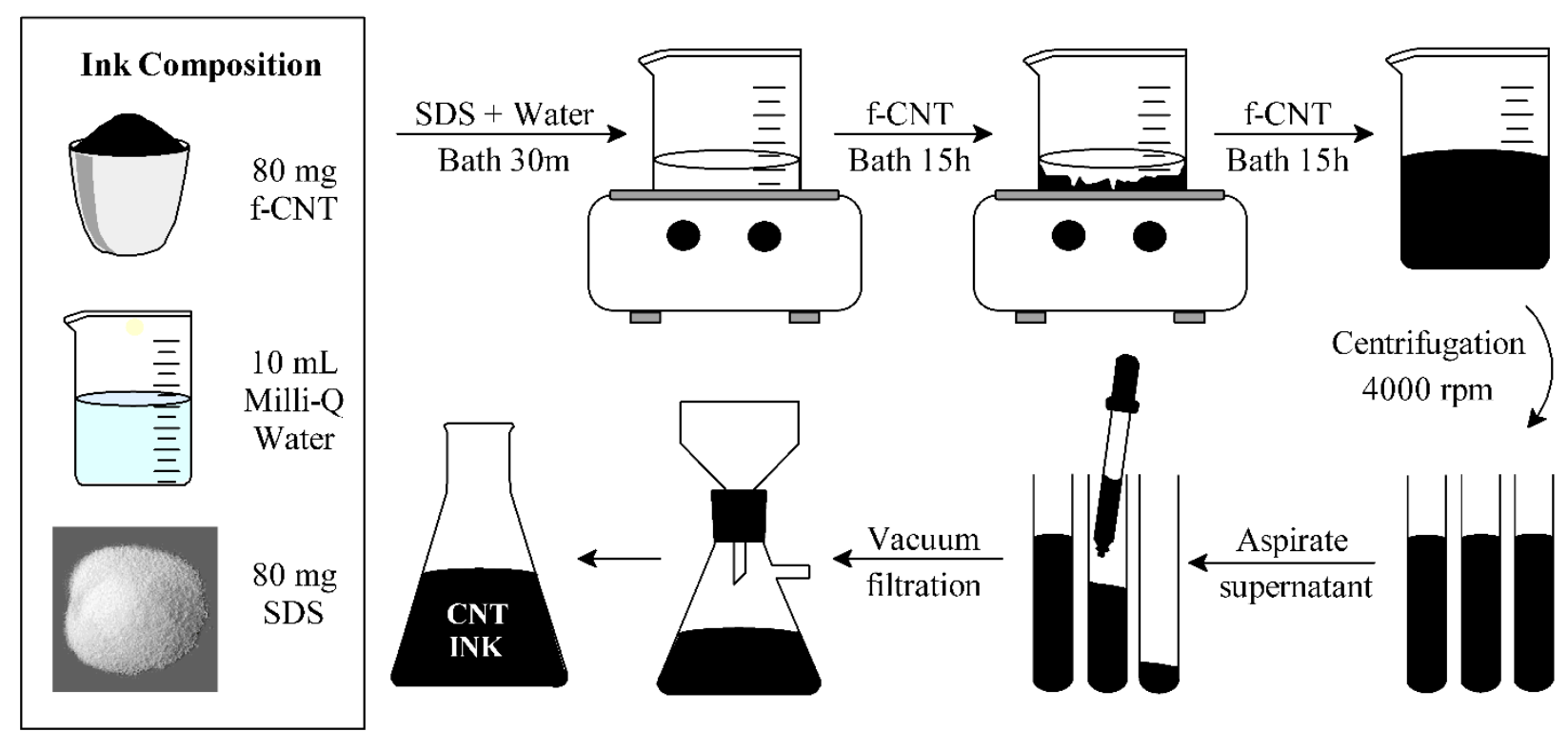

Figure 2. Representation of non-covalent functionalization of CNT using $f$-CNT/SDS

\section{Characterization tecniques}

The samples of SDS, CNT, $f-C N T, C N T / S D S$ and $f-C N T / S D S$ were characterized using different techniques. The Fourier transform infrared spectroscopy (FTIR) spectra were obtained in the region 
$4000-400 \mathrm{~cm}^{-1}$ by a Perkin-Elmer FTIR-8300 (Brazil) of Shimadzu using KBr pallets, only the SDS used ATR. The Scanning electron microscopy (SEM) images were recorded using JEOL JSM 300-LV (Brazil).

Electrochemical impedance spectroscopy (EIS) and cyclic voltammetry (CV) were carried out using Autolab PGSTAT204 controlled by NOVA 2.1 (Brazil). The three-electrode cell used carbon paste electrode (working electrode), $\mathrm{Ag} / \mathrm{AgCl}$ (reference electrode) and platinum wire (auxiliary electrode). The carbon paste electrode (CPE) was modified with the samples (SDS, CNT, f-CNT, $\mathrm{CNT} / \mathrm{SDS}$ and $\mathrm{f}-\mathrm{CNT} / \mathrm{SDS})$ and dried at $60{ }^{\circ} \mathrm{C}$. A solution with a redox probe $\left[\mathrm{Fe}(\mathrm{CN})_{6}\right]^{-3} /\left[\mathrm{Fe}(\mathrm{CN})_{6}\right]^{-4}$ was used and purged with $\mathrm{N}_{2}$ for 15 minutes.

The electrical properties were evaluated qualitatively and quantitatively. First, the CNT ink was used to draw a conductive path on a piece of paper, a LED was connected to the path and lit up using a battery. Then a digital two-point multimeter was used to measure the ohmic resistance of the CNT ink. UV-Vis was performed by the Shimadzu spectrophotometer UV-2550 using a quartz cuvette of $3.5 \mathrm{~mL}$ in the range $300-800 \mathrm{~nm}$.

\section{Results and discussion}

\section{Synthesis of carbon nanotube ink}

There are many challenges involved in the synthesis of water-based CNT ink. First, the hydrophobic surface of CNT has to be changed to hydrophilic to be efficiently dispersed in water [22,23]. The approach used in this work was a covalent and non-covalent functionalization to improve the carbon nanotube's dispersion stability in water. The result is called carbon nanotube (CNT) ink.

Each type of functionalization has some drawbacks and advantages. The covalent functionalization can severely degrade the mechanical properties of CNTs, while concentrate acids and/or strong oxidants used are not eco-friendly. Also, it disrupts the surface conjugated network, which can cause conductivity deterioration. However, the covalent bonding between functional groups and the CNT skeleton is stronger than the non-covalent interactions. Therefore, by combining covalent and noncovalent approaches, a better dispersion can be fabricated $[1,18]$.

The most frequent method employed to functionalize is the covalently defect functionalization of CNTs by nanotube oxidation. Strong acids can break the bonds between carbon atoms by inserting functional groups on the sidewalls of CNTs [19]. There are several procedures where acids, time, stirring and temperature are varied. A common procedure is to immerse CNTs in sulfuric acid $\left(\mathrm{H}_{2} \mathrm{SO}_{4}\right)$ and nitric acid $\left(\mathrm{HNO}_{3}\right)$ in the range 3:1 [18-21]. This functionalization method was performed and the photos of the process are presented in Figure 3.
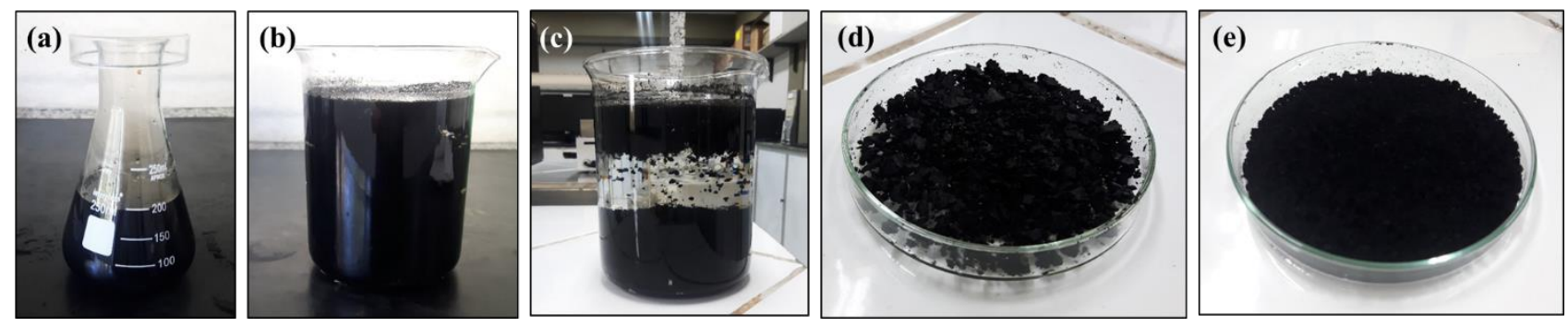

Figure 3. (a) Suspension of f-CNT after 20 hours; (b) after addition of water; (c) 2 hours after addition of water; (d) $f$-CNT after centrifugation; (e) $f$-CNT after vacuum filtration

The CNT powder was added to $\mathrm{H}_{2} \mathrm{SO}_{4} / \mathrm{HNO}_{3}$ suspension and sonicated. The sonication accelerates the oxidation process. This procedure results in the formation of carboxylic acid (-COOH), hydroxyl $(-\mathrm{OH})$ and carbonyl $(-\mathrm{C}=\mathrm{O})$ groups on the surface of nanotubes. The covalent functionalization causes 
the change of hybridization from $\mathrm{sp}^{2}$ to $\mathrm{sp}^{3}$ by incorporating the groups onto the CNT surface [22]. This process is illustrated in Figure 4(a).

(a)

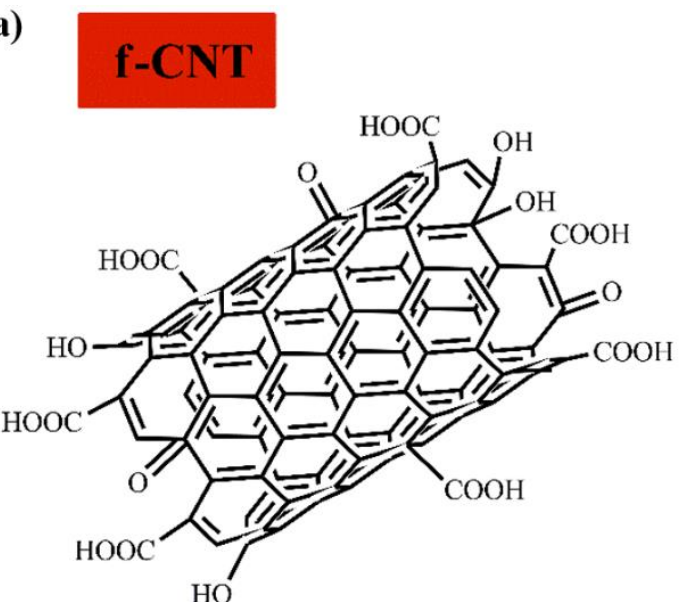

(b)
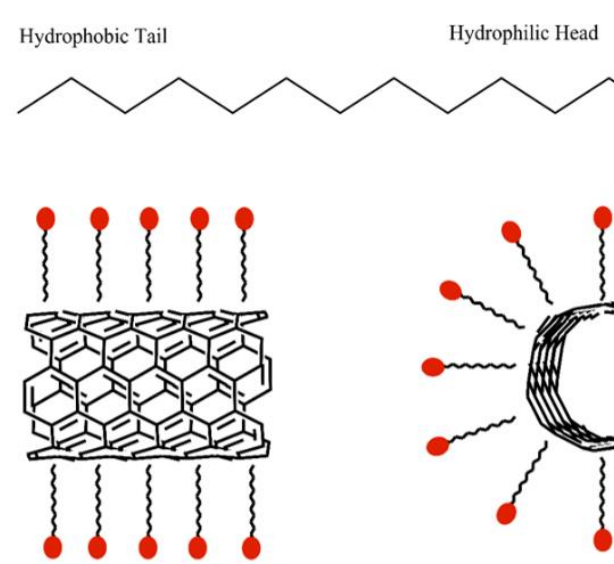

Side View

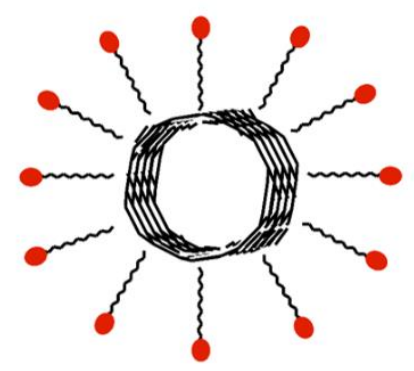

Cross section View

Figure 4. (a) Covalent functionalization of carbon nanotube using $\mathrm{H}_{2} \mathrm{SO}_{4}$ and $\mathrm{HNO}_{3}$ medium; (b) schematic SDS encapsulation of CNTs during non-covalent functionalization

After the suspension rest for 20 hours, the functionalization process was over. Figure 3(a) shows the suspension of $f-C N T$. However, $f$-CNT still need the purification step. First, as presented in Figure $3(b)$, water was added and let decanted for a couple of hours. The result is shown in Figure 3(c). The excess water was removed using a pipette, and the material was centrifuged at $4000 \mathrm{rpm}$ to separate the supernatant from the precipitate. Then the supernatant was washed five times with water to remove impurities. The resulting product was black and very granular, as shown in Figure 3(d). The last step was to mechanically grind the product in water with mortar and pestle. Then it was vacuum dried. The final product, called f-CNT, presented a more refined powder, as shown in Figure 3(e).

Next, non-covalent functionalization of $\mathrm{f}$-CNT was performed in order to improve the dispersion ability in the water. Non-covalent functionalization does not destroy the conjugated system of CNTs, preserving their aromatic structure. The process involves van der Waals, $\pi-\pi$ or $\mathrm{CH}-\pi$ interactions between the molecule and CNT surface [24]. Nowadays, two classes of molecules are mainly used for CNT dispersion: polymer wrapping and surfactant attachment.

Surfactants, such as sodium dodecyl sulfate (SDS), tend to lower the surface tension of liquids in a dispersion, preventing the formation of aggregates. The SDS molecule consists of two parts: the head part formed by hydrophilic groups and a tail formed by hydrophobic groups. The hydrophobic tail absorbs the surface of CNT and the hydrophilic head associates with water to improve the dispersion. This process is shown in Figure 4(b) [22,25,26].

However, the surfactant attachment in CNT dispersion may not occur spontaneously, and sonication can be used to agitate CNT particles and lower the agglomeration or bundles. In combination with the surfactant attachment, that mechanical method can promote the formation of uniform dispersion [28-30].

The sonication process converts the electric voltage into mechanical vibrations. That vibration is transferred to the dispersion of $\mathrm{f}-\mathrm{CNT} / \mathrm{SDS}$ and results in the formation and collapse of cavitation bubbles. The ultrasonic bath generates microscopic bubbles inside the liquid, filled with vapour or gas, also known as cavitation. The bubbles are periodically compressed and expanded as the ultrasonic waves are applied. Under unstable size, the bubble collapse and forms a hotspot with temperature and pressure over $5000 \mathrm{~K}$ and $500 \mathrm{~atm}$. These hotspots attack the CNT surface and 
break large aggregates. Then the SDS micelles wrap around the $\mathrm{f}-\mathrm{CNT}$, causing the dispersion in water [27,31-33]. This process can be seen in Figure 5.

(a)
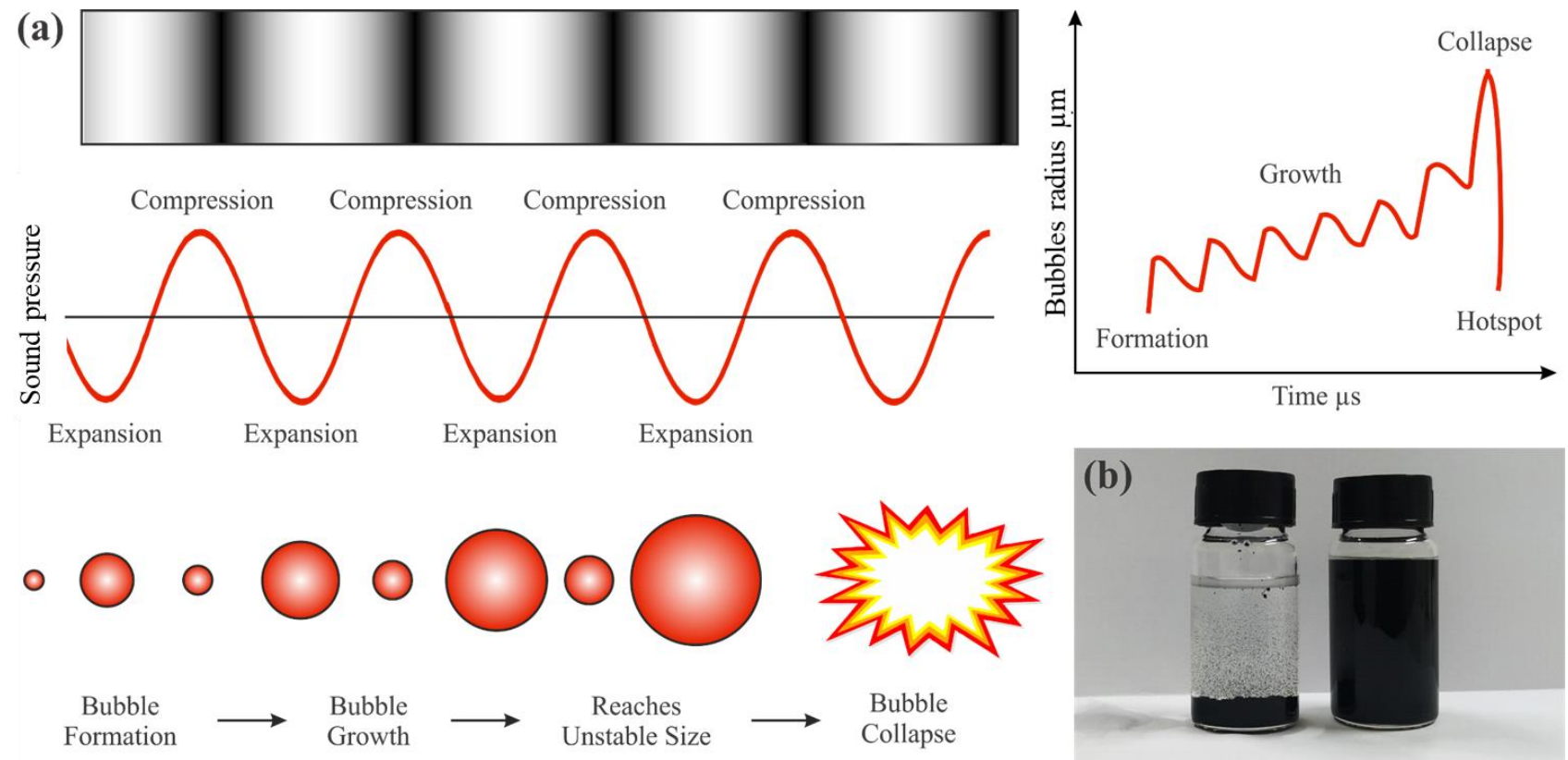

Figure 5. (a) Representation of the growth and collapse of cavitation bubbles due to applied acoustic field and associated pressure wave; (b) dispersions before and after sonication

Another possible explanation is that the mechanical energy provided by the ultrasonic bath overcomes attractive forces between aggregates of carbon nanotubes, leading to the dispersions of $\mathrm{f}$-CNT in water [27].

Therefore, sonication in combination with the surfactant attachment can promote uniform dispersion of $\mathrm{f}$-CNT in water. Although this method can shorten the CNT and cause defects, it is the most used method for CNT dispersion, especially in ink fabrication, where the dispersion must be without agglomerations or bundles. To ensure the uniformity, the dispersion was sonicated for 15 hours. Since studies have shown that the longer is the sonication time, the better is CNT dispersion and smaller is the particle size [27-29].

Then the dispersion was centrifuged to remove CNTs that did not disperse. The supernatant collected was also vacuum filtered to separate any agglomeration or bundles left, ensuring a welldispersed dispersion [24]. The final product is called CNT ink. The dispersion before and after the sonication process can be observed in Figure 5(b).

\section{Dispersion studies}

Generally, non-polar compounds are most soluble in non-polar solvents and polar compounds in polar solvents. That is, solids that have similar polarities tend to be soluble in each other. Therefore, the character of a molecule or compound affects dispersion forces in solute-solvent interactions $[33,34]$. Dispersion studies were conducted to evaluate the efficiency of dispersing material in aqueous solutions. Figure 6(a), (b) and (c) shows dispersions 5 minutes after sonication, 24 hours after sedimentation, and after centrifugation at $4000 \mathrm{rpm}$, respectively.

The hydrophilic head in SDS exhibits characteristics of a polar compound. Thus, SDS is soluble in water $(200 \mathrm{mg} / \mathrm{ml})$, yielding a clear, colorless solution [35]. The solution was highly stable, even after centrifugation. 
CNT naturally exhibits an entire hydrophobic surface due to the $\mathrm{sp}^{2}$ hybridized bonds. The CNTs tend to form bundles, ropes and agglomerates, becoming insoluble in water due to the Van der Waals attraction forces between nanotubes [36]. However, 5 minutes after sonication, the dispersions were apparently good. This can be explained because the ultrasonic bath exfoliates CNTs improving their dispersion. But this effect did not last long since CNT dispersion starts to sediment after a few hours and completely aggregates after centrifugation [37,38].
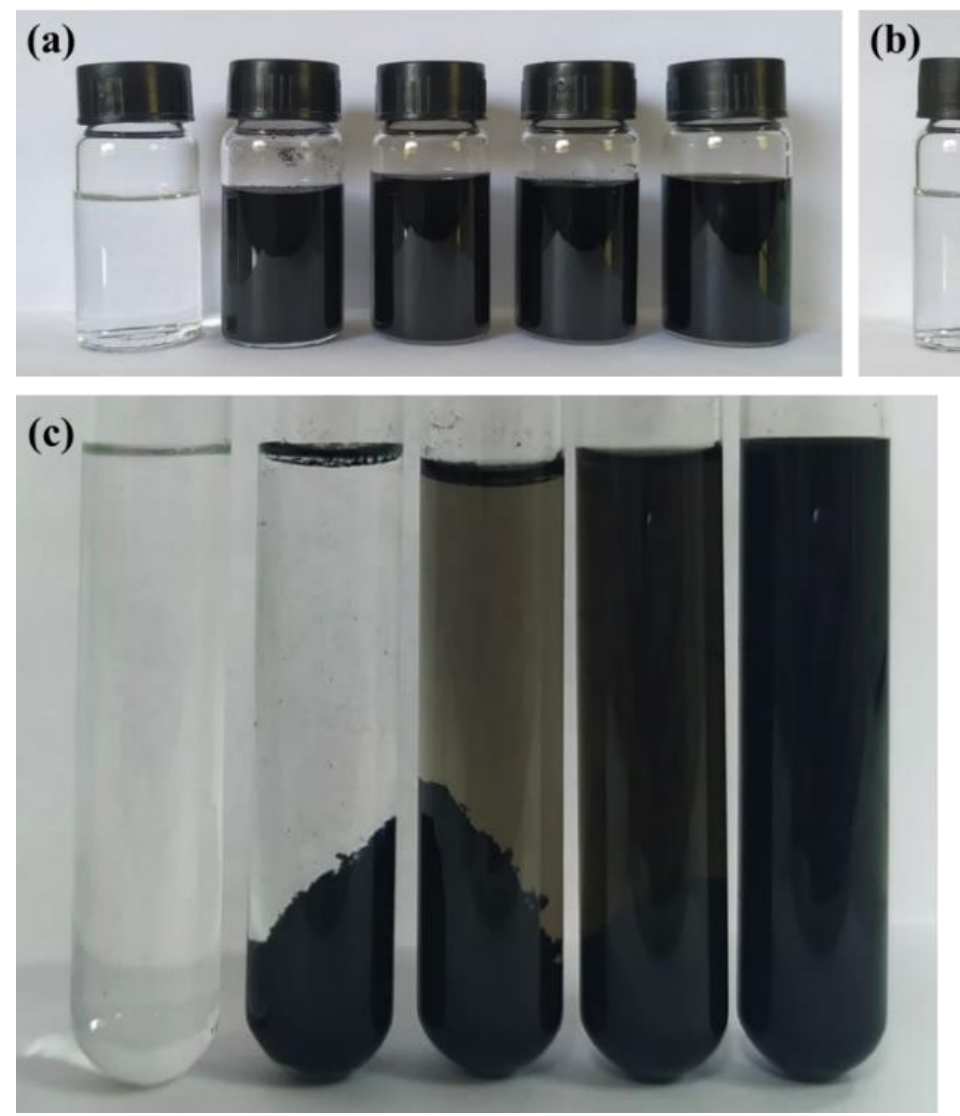

(b)
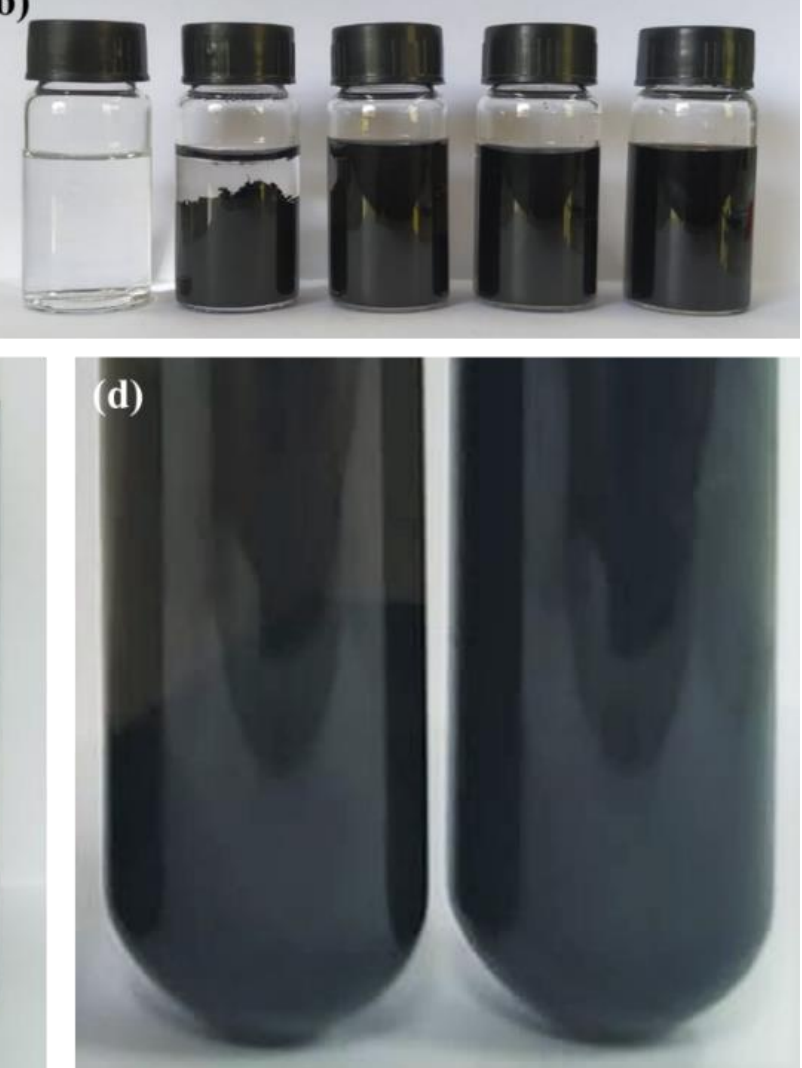

Figure 6. SDS, CNT, f-CNT, CNT/SDS, $f$-CNT/SDS dispersed in water: (a) 5 minutes after sonication; (b) after 24 hours; (c) after centrifugation at $4000 \mathrm{rpm}$; (d) zoom of CNT/SDS and $f$ CNT/SDS after centrifugation at $4000 \mathrm{rpm}$

However, this behavior can be avoided. The functionalization allows CNTs to disperse more easily. Several functional groups $(-\mathrm{COOH},-\mathrm{OH}$ and $-\mathrm{C}=\mathrm{O})$ were randomly distributed on the CNT surface, increasing the polarity and making the compound more hydrophilic [38]. The f-CNT formed a relatively stable dispersion in water that was kept that way after sonication but after centrifugation the f-CNT sediments. Therefore, only the covalent functionalization was not enough to form a stable dispersion.

Similar behavior was observed for CNT/SDS. SDS improves the dispersion of CNTs through hydrophobic/hydrophilic interactions $[1,14]$. The dispersion was more stable than $\mathrm{f}$-CNT in water. Nevertheless, after centrifugation, most CNT was at the bottom of the test tube. This behavior can be seen more clearly in Figure 6(d). Also, the non-covalent functionalization alone was not enough to disperse CNTs effectively.

Consequently, combining the covalent and non-covalent functionalization, it was possible to fabricate a carbon nanotube ink ( $f$-CNT/SDS) that exhibits excellent storage stability. As previously discussed, this method includes the insertion of functional groups and absorption of the hydrophobic tail of SDS in the CTN surface. As can be observed, even after centrifugation, the CNT ink remains well-dispersed. Thus, the dispersion studies made possible some speculation about 
changes according to the dispersion composition and helped to verify that the combination of both functionalizations was the most effective way to fabricate a stable CNT ink.

The CNT ink fabricated remained remarkably stable over several months. Also, before use, it is not required to sonicate or stir the ink. This resulted in a conductive ink with long-term stability. Although other researchers have already proposed routes for CNT ink using SDS, most of them do not address the stability issue and how only SDS may result in CNT ink with low stability.

\section{Infrared spectroscopy}

After dispersion studies, the materials were characterized by infrared (IR) spectroscopy. The spectra of SDS, CNT, f-CNT, CNT/SDS and f-CNT/SDS were used to investigate the composition and structure of each sample, as shown in Figure 7 . The results can also be used to prove the efficiency of covalent and non-covalent functionalization processes.
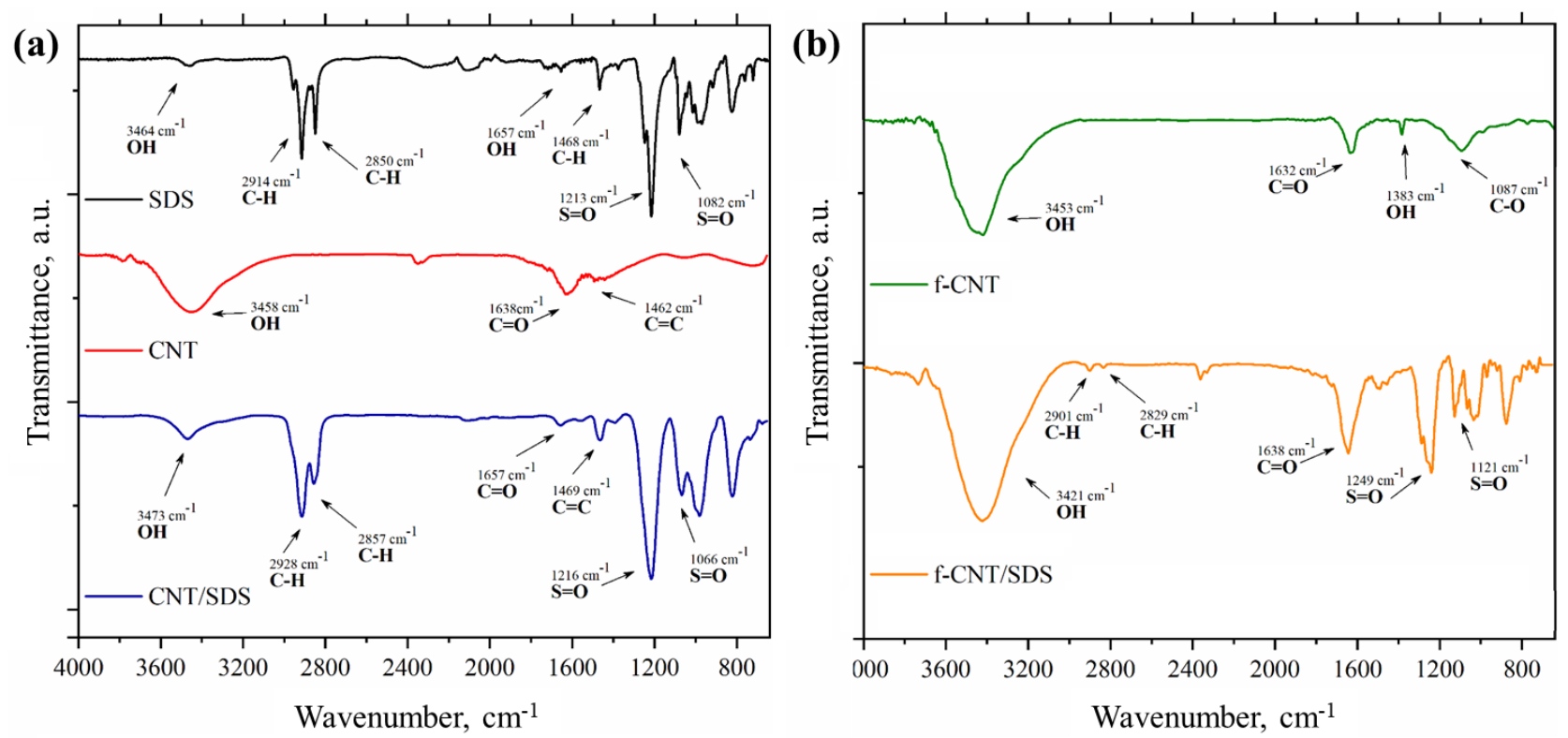

Figure 7. IR spectra of SDS, CNT, CNT/SDS, $f-C N T, f-C N T / S D S$ at $4000-750 \mathrm{~cm}^{-1}$

The SDS spectrum shows a band at $3464 \mathrm{~cm}^{-1}$ assigned to $\mathrm{OH}$ asymmetric stretching and at $1657 \mathrm{~cm}^{-1}$ due to $\mathrm{OH}$ bending vibration. These bands are probably associated with the hydroxyl groups of physically adsorbed water molecules $[40,41]$. The spectrum has another three bands related to C$\mathrm{H}$ symmetric stretching vibration $\left(1468 \mathrm{~cm}^{-1}\right), \mathrm{C}-\mathrm{H}$ symmetric $\left(2850 \mathrm{~cm}^{-1}\right)$ and asymmetric $\left(2914 \mathrm{~cm}^{-1}\right)$ stretching vibration of $\mathrm{CH}_{2}$. These can be attributed to the chain of 12 carbon atoms in the SDS molecule [42]. The $\mathrm{SO}_{2}$ asymmetric vibration $\left(1213 \mathrm{~cm}^{-1}\right)$ due to the sulfate group of SDS is the most intense band in the spectrum. This band is a combination of several overlapping peaks, and usually, it can observe a shoulder. The band at $1082 \mathrm{~cm}^{-1}$ corresponds to the $\mathrm{SO}_{2}$ symmetric vibration [43-45].

The spectrum from pristine CNT shows an intense band at $3458 \mathrm{~cm}^{-1}$, characteristic of the $\mathrm{OH}$ stretch of the hydroxyl group of water. The peak at $1638 \mathrm{~cm}^{-1}$ assigns carbonyl $(C=O)$ stretching vibration of carboxyl groups $[46,47]$. This band may be due to ambient moisture. All the samples (SDS, CNT, $\mathrm{f}-\mathrm{CNT}$, CNT/SDS and $\mathrm{f}-\mathrm{CNT} / \mathrm{SDS}$ ) were sonicated in water and then dried before characterization to ensure a homogeneous material and compare materials in the same preparation conditions. Another explanation is that the bands are attributed to the initial purity of CNTs. Therefore, it can be observed that CNTs contain defects due to functional groups, which may be formed during their fabrication process. Also, the band at $1462 \mathrm{~cm}^{-1}$ is assigned to the $\mathrm{C}=\mathrm{C}$ stretching of CNT. This indicates the presence of carbon double bond $(C=C)$, confirming the $\mathrm{sp}^{2}$ structure of CNTs $[48,49]$. 
As expected, the bands of CNT at $3473 \mathrm{~cm}^{-1}$ (OH stretch), $1657 \mathrm{~cm}^{-1}$ (C=O stretch) and $1469 \mathrm{~cm}^{-1}$ ( $\mathrm{C}=\mathrm{C}$ stretch) are present in the $\mathrm{CNT} / \mathrm{SDS}$ spectra. Also, the characteristics bands of sulfate groups (1216 and $1066 \mathrm{~cm}^{-1}$ ) of SDS are both present in the CNT/SDS, indicating the existence of surfactants on the CNT surface $[43,50]$.

During the covalent functionalization, the carbon hybridization of CNTs changed from $\mathrm{sp}^{3}$ to $\mathrm{sp}^{2}$, causing the breakage of $\mathrm{C}=\mathrm{C}$. As shown in the $\mathrm{f}-\mathrm{CNT}$ spectrum, the band disappeared, indicating the covalent functionalization. The $\mathrm{f}$-CNT also presents a very broad band at $3453 \mathrm{~cm}^{-1}$ attributed to the $\mathrm{OH}$ stretch of the hydroxyl group from different oxygenated functional groups [51]. The band at $1632 \mathrm{~cm}^{-1}$ from $\mathrm{C}=\mathrm{O}$ stretching bonds indicates that the CNT has a carbonyl group due to the functionalization treatment. The band at $1383 \mathrm{~cm}^{-1}$ originates from $\mathrm{OH}$ stretching in the introduced $-\mathrm{COOH}$ due to the covalent functionalization [52,53]. A small peak at $1087 \mathrm{~cm}^{-1}$ can be associated with the $\mathrm{C}-\mathrm{O}$ bond related to alcohol groups introduced in the functionalization processes [54]. These results confirm that the carbon nanotubes have been well functionalized with carboxyl functional $(-\mathrm{COOH})$, carbonyl $(\mathrm{C}=\mathrm{O})$ and hydroxyl $(-\mathrm{OH})$ groups $[55,56]$.

The $\mathrm{f}-\mathrm{CNT} / \mathrm{SDS}$ spectrum shows the bands of SDS related to sulfate groups (1249 and $\left.1121 \mathrm{~cm}^{-1}\right)$, implying that SDS was successfully adsorbed on the $\mathrm{f}-\mathrm{CNT}$ surface. The stretching vibration of $\mathrm{CH}_{2}(2901$ and $2829 \mathrm{~cm}^{-1}$ ) attributed to the carbon chain of SDS is also observed. However, the intensity of the bands related to the $\mathrm{C}-\mathrm{H}$ became significantly weak after the addition of SDS. This happens because the SDS has been adsorbed by hydrophobic interaction between surfactant hydrocarbon chains and CNT surface [57]. The bands of $\mathrm{OH}$ stretch of the hydroxyl group $\left(3421 \mathrm{~cm}^{-1}\right)$ and $\mathrm{C}=\mathrm{O}$ stretching vibration of carboxyl groups $\left(1638 \mathrm{~cm}^{-1}\right)$ decreased due to the interaction between $\mathrm{f}-\mathrm{CNT}$ and SDS. However, the presence of these bands indicates the presence of functional groups $(-\mathrm{COOH}, \mathrm{C}=\mathrm{O}$ and $-\mathrm{OH})$.

The interpretation of spectra in the IR region suggests that the covalent and non-covalent functionalizations were effective in the CNT ink fabrication. The CNT structure presented several functional groups such as carboxylic acid $(-\mathrm{COOH})$, hydroxyl $(-\mathrm{OH})$ and carbonyl $(-\mathrm{C}=\mathrm{O})$. Meanwhile, the surfactant SDS was attached to the previously functionalized CNT. As shown before, the combination of two ways of functionalization allows the formation of well-dispersed ink.

\section{Scanning electron microscopy}

The scanning electron microscopy (SEM) technique was used to study the topography of materials SDS, CNT, $f-C N T, C N T / S D S$, and f-CNT/SDS. The goal was to evaluate the effectiveness of the covalent and non-covalent functionalization and the homogeneity of the material. The results are presented in Figure 8.
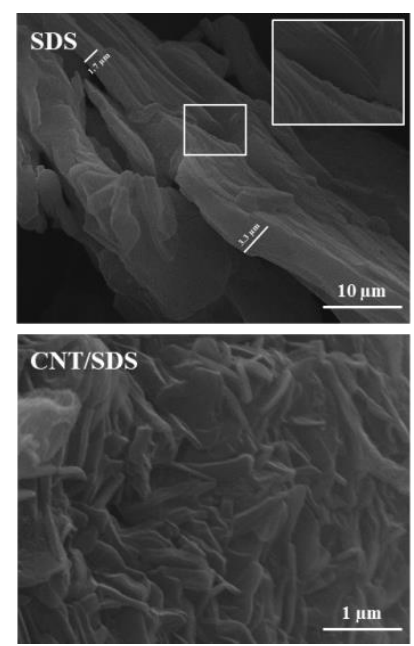
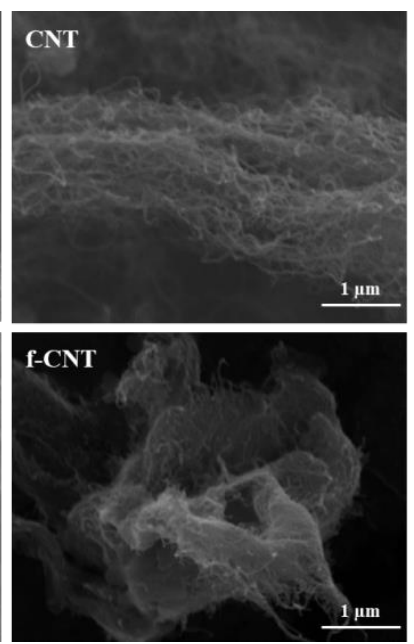

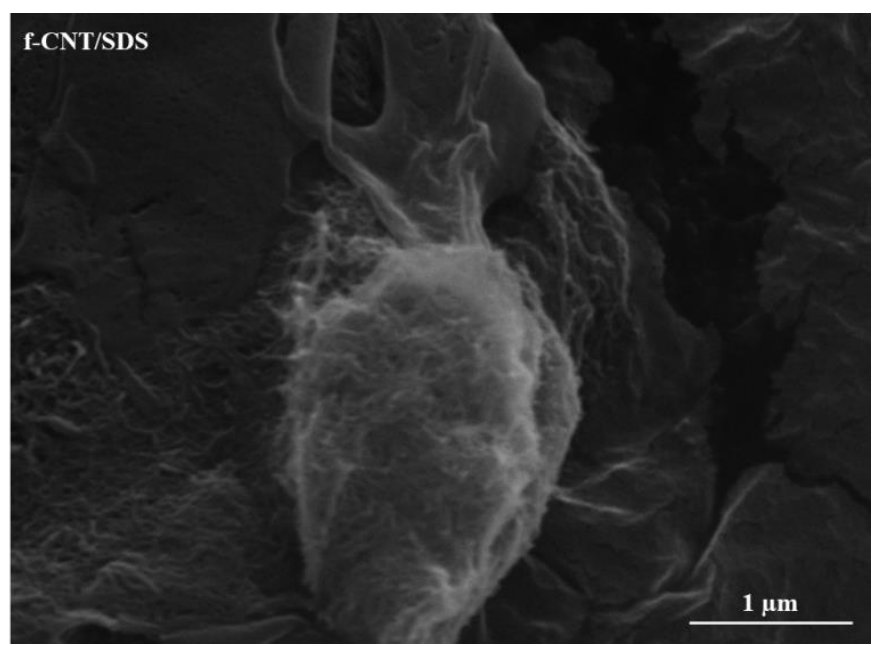

Figure 8. SEM images of SDS, CNT, $f-C N T, C N T / S D S$ and $f-C N T / S D S$ 
The SDS morphology revealed main blocks with plate-like appearance and regular edges. The SDS thickness is around 1.7 to $3.3 \mu \mathrm{m}$. At high magnification, SDS shows a dense surface without pores or particular features $[58,59]$. The image of pristine CNT shows a surface with bundles of tangled tubes. It reveals uniform morphology without any agglomeration. The CNTs are not aligned in parallel to one another and the distribution is individual and randomly oriented. The size of tube diameter ranged from 14 to $39 \mathrm{~nm}[60,61]$. The diameters of CNT/SDS are much higher than the CNT. That means the SDS surfactant layer was grafted to the surface of CNTs and changed their shape. SDS keeps the CNTs apart, preventing their entanglement and agglomeration, resulting in a rod-like homogeneous surface [62].

The morphology of CNTs slightly changed after the covalent functionalization. As seen in the $f$ CNT image, the surface presents a rougher surface structure due to the attachment of oxygenated functional groups. More agglomeration can be observed on the f-CNT surface than the pristine CNT. The sidewalls of $f-C N T$ are considerably defected. There were no obvious impurities on its surface left during the acid treatment $[63,64]$. Also, the functional groups on $\mathrm{f}$-CNT surface reduce van der Waals forces, reducing the strong tendency to form bundles [65].

The f-CNT/SDS image shows spherical geometry with diameters near $1.75 \mu \mathrm{m}$ formed by irregular agglomerates of $\mathrm{f}-\mathrm{CNT}$. Since the concentration of SDS was above the critical micelle concentration (CMC), the change in the $\mathrm{f}$-CNT shape was observed due to the effective micelle formation. As expected, the structure aggregates to form cylindrical micelles. In the background, the remaining SDS was observed [64-66]. This result indicates that both covalent and non-covalent functionalization in the fabrication of CNT ink was effective.

\section{Electrochemical characterization}

The materials SDS, CNT, f-CNT, CNT/SDS and f-CNT/SDS were evaluated for electrochemical properties using cyclic voltammetry. For that purpose, the conventional carbon paste electrode (CPE) was modified with each material, dried at $60^{\circ} \mathrm{C}$, and used in a three-electrode cell with $\mathrm{Ag} / \mathrm{AgCl}$ reference electrode and a platinum wire auxiliary electrode. The cyclic voltammograms are presented in Figures 9(a) and 9(b).
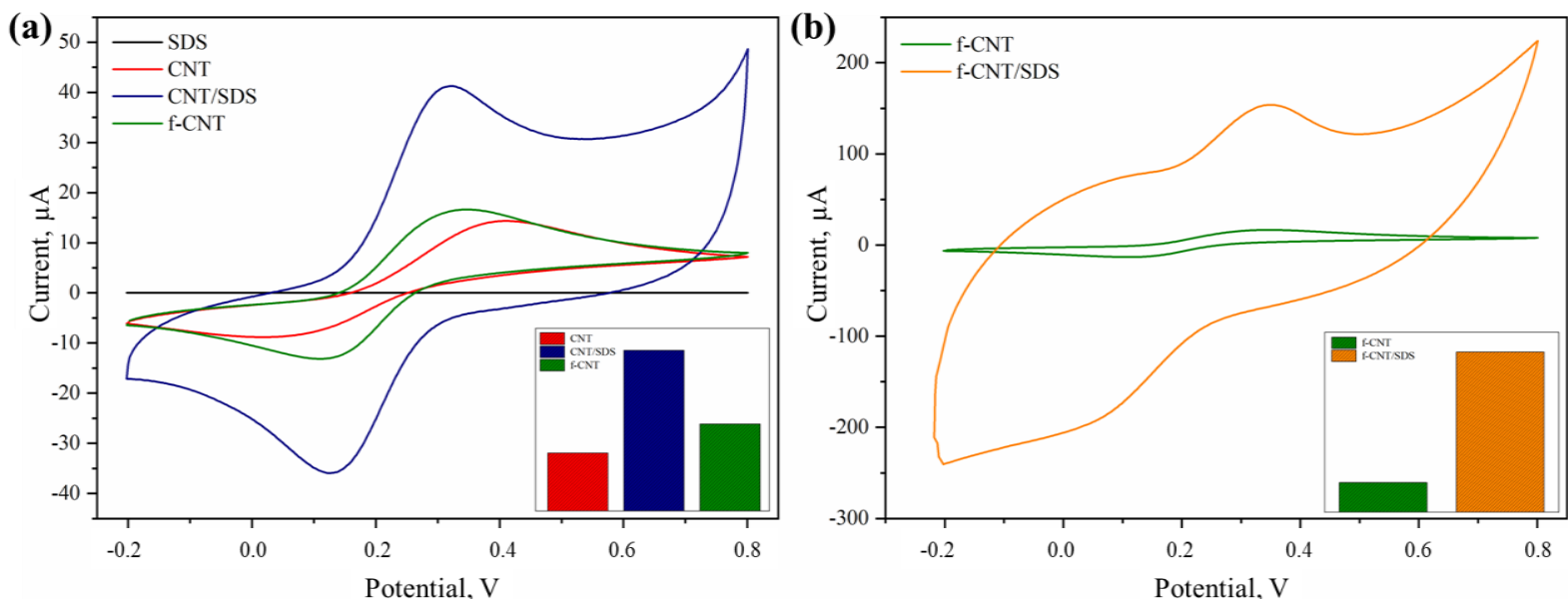

Figure 9. (a) Cyclic voltammograms (scan rate $=25 \mathrm{mV} \mathrm{s}^{-1}$ ) of $1.0 \mathrm{mM} \mathrm{K}_{3}\left[\mathrm{Fe}(\mathrm{CN})_{6}\right]$ in $0.1 \mathrm{MPBS}$, pH 7.0 at CPE modified with: (a) SDS, CNT, CNT/SDS; (b) f-CNT and f-CNT/SDS; Insets: oxidation peak intensity vs. modifier material

SDS is a synthetic organic compound. Due to the covalent bonds in its structure, electrons cannot move around freely, and therefore SDS does not conduct electricity. That is confirmed by the absence of electrochemical behavior in the voltammogram. This result indicates the electrical 
isolation nature of SDS [68]. The voltammogram for the CNT modifier exhibited the characteristic oxidation and reduction peaks for the redox couple $\left.\mathrm{Fe}(\mathrm{CN})_{6}\right]^{3-} /\left[\mathrm{Fe}(\mathrm{CN})_{6}\right]^{4-}$. Since the carbon atom has four electrons and only three are used to form the covalent bonds, a remaining electron is highly mobile and available for electrical conduction $[69,70]$. As a consequence, CNT is an excellent electrical conductor, which results in good electrochemical behavior. As observed in the voltammogram of CNT/SDS, the presence of SDS improves the peak current by $177 \%$ compared to the CNT response. This enhances indicates that SDS plays an important role in facilitating the electron transfer kinetics at the electrode/solution interface. That happens because of the high specific area, porous structure and suitable pore size of SDS, resulting in a higher peak current [71]. As can be observed for f-CTN behavior, the redox peaks increased $22 \%$ after the covalent functionalization compared to the CNT response. The presence of functional groups facilitates the electron transfer improving the electrical conductivity. That confirms the effective introduction of functional groups in the CNT surface through the acid treatment $[72,73]$.

Finally, the behavior of the CNT ink that contains both f-CNT and SDS was evaluated. The electrochemical response showed an increase of $315 \%$ compared to the $f-C N T$ voltammogram. As discussed, the presence of SDS facilitates the electron transfer kinetics resulting in a higher peak current. That behavior is observed in the $\mathrm{f}$-CNT/SDS response. Also, a sudden change in the shape of the voltammogram to a more resistive profile is noticed. The inclination and small distortion are results of the SDS isolation nature [74]. The voltammetric behavior indicates that the use of both functionalizations showed a better electrochemical response. This demonstrates that the composition of the CNT ink (f-CNT/SDS) can be used to fabricate a conductive ink.

\section{Electrochemical impedance spectroscopy}

Electrochemical impedance spectroscopy (EIS) was used to investigate each material's conductivity and interface resistance [75]. Figure 10(a) and 10(b) presents the Nyquist plots of CNT, $\mathrm{f}-\mathrm{CNT}, \mathrm{CNT} / \mathrm{SDS}$ and $\mathrm{f}-\mathrm{CNT} / \mathrm{SDS}$.

The experiments were conducted in a three-electrode cell using differently modified CPE as WE in PBS containing $1.0 \mathrm{mM}$ of $\mathrm{K}_{3}\left[\mathrm{Fe}(\mathrm{CN})_{6}\right]$, at $0.185 \mathrm{~V}$. First of all, it is important to mention that the EIS of SDS was impossible to conduct. This can be explained due to the high solubility in water, where SDS may probably leach to the electrolyte. However, the isolated nature of SDS was already proved using cyclic voltammetry $[76,77]$.

The diameter of the semicircle in the Nyquist diagram corresponds to the charge transfer resistance $\left(R_{\mathrm{ct}}\right)$ of redox reaction at the electrode surface. The larger is the diameter of the semicircle, the higher is $R_{\mathrm{ct}}$ as a consequence of the higher resistance of the modifier material. As observed, the semicircle decreases from CNT to f-CNT. As discussed in the last topic, CNT is an excellent electrical conductor. Nevertheless, the functional groups improve the electron transfer, consequently decreasing the charge transfer resistance. This results in a smaller $R_{\text {ct }}$ value, compared to the CNT plot $[78,79]$. The Nyquist plots of CNT and f-CNT were fitted to the Randles equivalent circuit, shown in Figure 10(c), and the resulting values are presented in Figure 10(d). The constant phase element (CPE) related parameter increases from CNT to f-CNT, confirming the lower impedance after covalent functionalization [80].

Although CNT and f-NTC displayed a large semicircle, the EIS of CNT/SDS and f-CNT/SDS showed straight lines. The absence of the semicircle in the Nyquist plots is indicative of fast electron transfer, resulting in good conductivity and small interface resistance $[76,80]$. So, the Bode plots will be used to evaluate the impedance of CNT/SDS and f-CNT/SDS. 

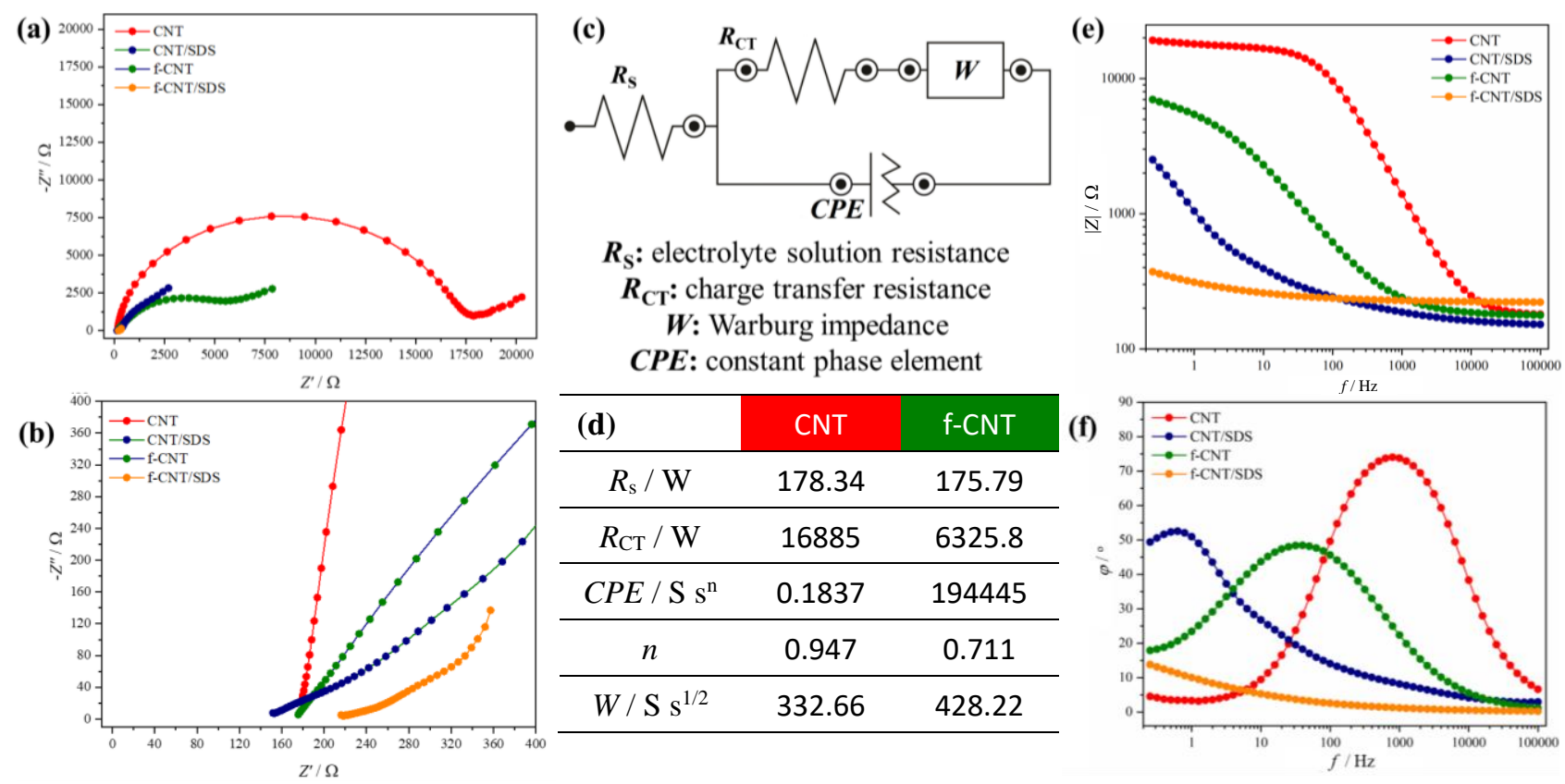

\begin{tabular}{|ccc}
\hline (d) & CNT & f-CNT \\
\hline$R_{\mathrm{S}} / \mathrm{W}$ & 178.34 & 175.79 \\
\hline$R_{\mathrm{CT}} / \mathrm{W}$ & 16885 & 6325.8 \\
\hline$C P E / \mathrm{S} \mathrm{s}{ }^{\mathrm{n}}$ & 0.1837 & 194445 \\
\hline$n$ & 0.947 & 0.711 \\
\hline$W / \mathrm{S} \mathrm{s}^{1 / 2}$ & 332.66 & 428.22 \\
\hline
\end{tabular}

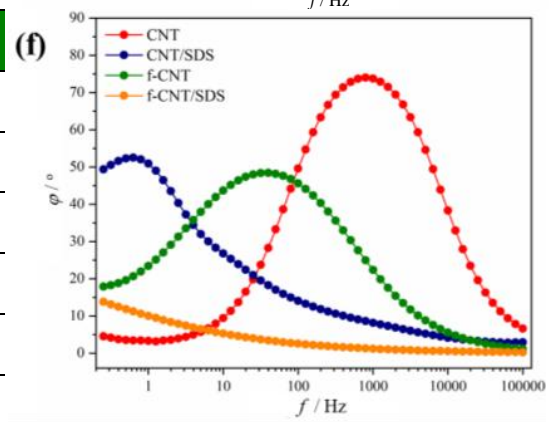

Figure 10. (a) Nyquist diagram; (b) Nyquist diagram in a different scale; (c) Randles equivalent circuit used to fit impedance data; (d) EIS fitting impedance parameters of CNT and f-CNT; (e) Bode magnitude plots and (f) Bode phase angle plots for CNT, CNT/SDS, $f$-CNT, f-CNT/SDS modified CPE in $0.1 \mathrm{M} \mathrm{PBS,} \mathrm{pH} \mathrm{7.0,}$ containing $1.0 \mathrm{mM} \mathrm{K}_{3}\left[\mathrm{Fe}(\mathrm{CN})_{6}\right]$

Bode plots allow the examination of the absolute impedance and phase angle $(\varphi)$ as a function of frequency. It is desirable to use Bode plots when data scatter prevents adequate fitting of the Nyquist semicircle. The results are shown in Figures 10(e) and 10(f). The low-frequency impedance decreased from CNT to CNT/SDS since SDS facilitates the electron transfer by improving the electrical conductivity. This behavior is also observed comparing f-CNT and f-CNT/SDS plots. The low-frequency impedance decreased due to the presence of SDS too. It is also seen that the impedance rarely varies at high frequencies but increases sharply with the decrease in frequency. Therefore, the high-frequency impedance is mostly stabilized for all materials [80-82].

Concerning the phase angle plot, the maximum phase angle decreases at lower frequencies due to the influence of charge transfer resistance. This is related to the resistance of each material. The results are in agreement with the other plots, where CNT is the most resistive material and $\mathrm{f}-\mathrm{CNT} / \mathrm{SDS}$ is the most conductive [79]. In conclusion, the CNT ink (f-CNT/SDS) has a better composition for good conductive ink.

\section{Electrical properties}

As the goal is to use CNT ink as conductive ink, it is crucial to evaluate the conductivity of the ink. For this, the CNT was used to paint a conductive path on a piece of photo paper (108 g) with the help of a paintbrush, as seen in Figure 11(a). Then the CNT path painted in the paper substrate was used to light up a light-emitting diode (LED), demonstrating the conductivity of ink empirically, as shown in Figure 11(b).

To quantify the ink conductivity, the ohmic resistance was measured using a two-point multimeter. Grisales et al. [83] discussed some variables that can affect the measurement using the multimeter and how to avoid them. The main variables were thickness, drying, distance and pressure. Hence, to measure the ohmic resistance of the CNT ink, those factors were kept constant.

First, the number of layers or thicknesses of CNT ink painted on the paper substrate was chosen. The conductivity of the CNT ink is dominated by the inherent conductivity of nanotubes. It was 
observed that the resistance was reduced after each layer of ink. But there is a critical thickness when the resistance cannot decrease much further [83]. This behavior was observed at 20 layers of CNT ink in the paper substrate.

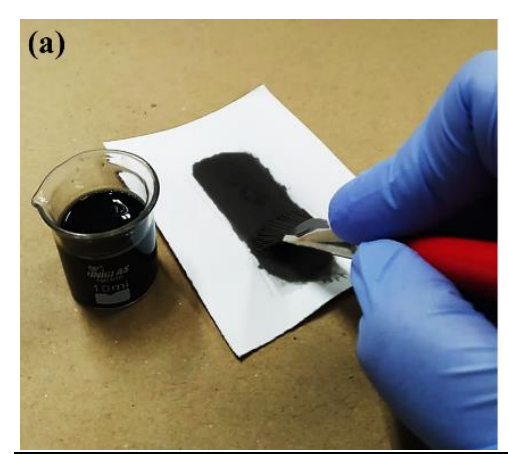

(d)

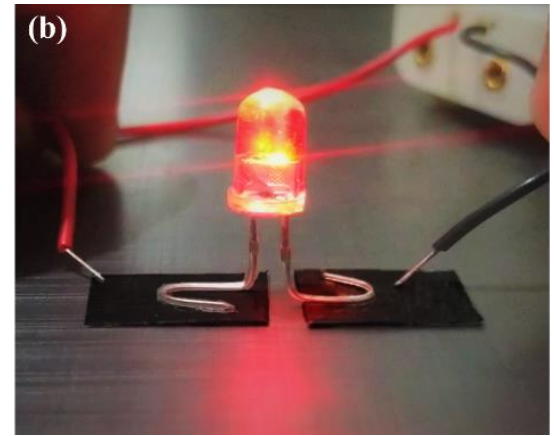

Before sintering

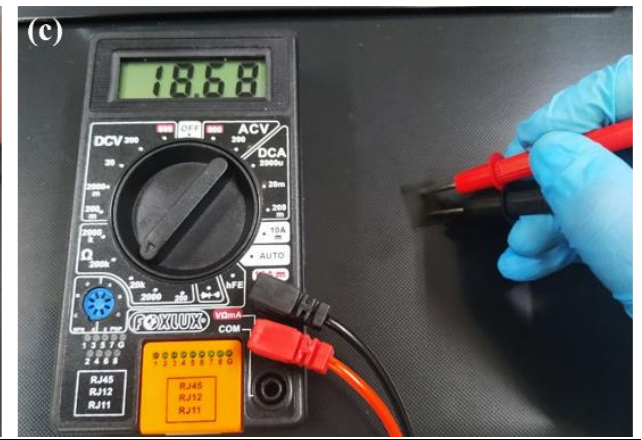

After sintering

Ohmic resistance, $\mathrm{k} \Omega$

\begin{tabular}{ccc}
\hline Measuremet 1 & 18.68 & 18.71 \\
\hline Measuremet 1 & 18.62 & 18.65 \\
\hline Measuremet 1 & 18.55 & 18.74 \\
\hline Average \pm SD & $18.62 \pm 0.05$ & $18.70 \pm 0.04$ \\
\hline
\end{tabular}

Figure 11. (a) Painting a piece of paper with CNT ink; (b) simple test of ink conductivity using LED;

(c) measuring the ohmic resistance of CNT ink using multimeter; (d) values of ohmic resistance before and after the sintering process

Then it is important to make sure that the water evaporates completely and the ink is completely dried at the time of measurement. For that purpose, the painted substrate can be left to dry at room temperature for 30 minutes or dried in a laboratory oven at $70^{\circ} \mathrm{C}$ for 10 minutes [84]. The value of the resistance is measured between two points. The CNT was painted on a piece of paper of $1.5 \times 2.0 \mathrm{~cm}$ and the probes of the multimeter were placed at $1 \mathrm{~cm}$ separation. It is relevant to maintain this separation constant in each measurement $[83,85]$.

Finally, the pressure applied with the probes can affect the results. To minimize these variations, only one person performed all measurements and the value was registered after 10 seconds to allow the resistance to become stable [83]. Considering all these variables, the ohmic resistance was measured three times, as shown in Figure 11(c), resulting in the average resistance of CNT ink of $18.62 \mathrm{k} \Omega$.

Usually, the conductive inks require the sintering process post-printing. In this process, the particle in ink will coalesce to form a continuous electrical contact. Also, the sintering removes dispersant and auxiliaries, which will affect the electrical conductivity [85]. Therefore, a simple test of how the ohmic resistance behaves before and after the sintering process is shown in Figure 11(d).

The sintering process was conducted at $100^{\circ} \mathrm{C}$ for 20 minutes. That temperature was chosen since it is the highest possible without burning the paper substrate. As observed, after the sintering process, the ohmic resistance of the CNT ink does not change, indicating that CNT ink does not require the sintering process. This is an appealing result since it facilitates the use of CNT ink, excluding the additional step.

Because of high conductivity, the CNT ink is often used to develop electrochemical sensors. Therefore, to evaluate the electrochemical behavior of the synthesized ink, the CNT ink was used to fabricate the working electrodes of an electrochemical sensor. For that, a piece of paper painted with CNT ink was cut into the dimensions of $4 \times 1.5 \mathrm{~cm}$, as shown in Figure 12(a). Then this paper was used as the working electrode (WE) of a three-electrode cell, seen in Figure 12(b). The cyclic voltammogram is presented in Figure 12(c). The voltammetric studies were carried out in the presence and absence 
of $\mathrm{K}_{3}\left[\mathrm{Fe}(\mathrm{CN})_{6}\right]$. As shown in the cyclic voltammogram recorded in the presence of $\mathrm{K}_{3}\left[\mathrm{Fe}(\mathrm{CN})_{6}\right]$, two peaks corresponding to the redox couple $\left[\mathrm{Fe}(\mathrm{CN})_{6}\right]^{4-} /\left[\mathrm{Fe}(\mathrm{CN})_{6}\right]^{3-}$ are observed. However, the voltammogram profile exhibits a small distortion and inclination. This resistive behavior is due to the presence of SDS in the ink composition [87]. No voltammetric peaks and a low background current are observed in the absence of $\mathrm{K}_{3}\left[\mathrm{Fe}(\mathrm{CN})_{6}\right]$. This indicates that the synthesized $\mathrm{CNT}$ ink has a prominent potential to fabricate electrochemical sensors.
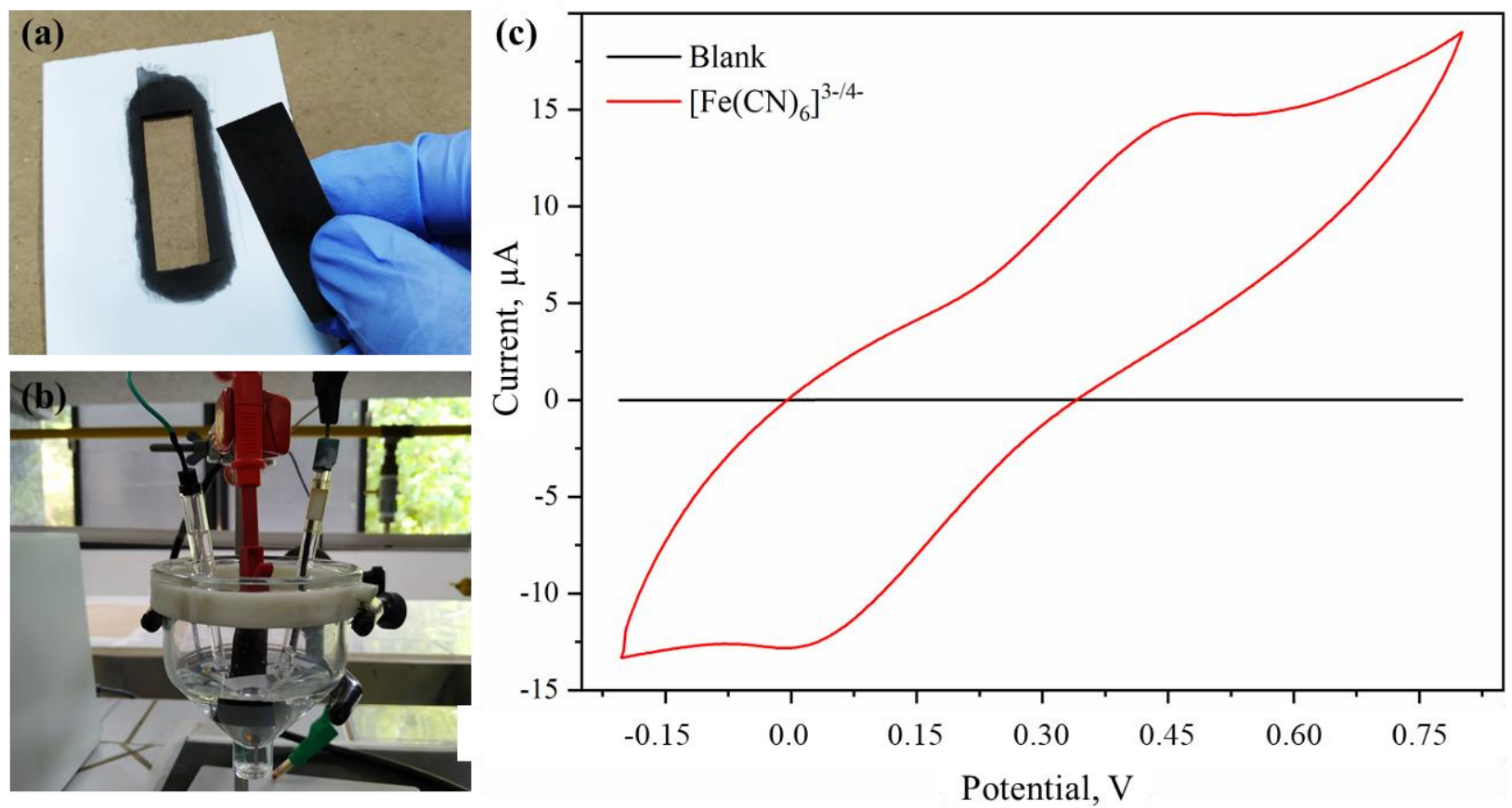

Figure 12. (a) The working electrode (WE) fabricated with CNT ink; (b) three-electrode cell containing CNT ink on the paper as WE, platinum wire as an auxiliary electrode (AE) and $\mathrm{Ag} / \mathrm{AgCl}$ as reference electrode (RE); (c) CVs (scan rate $=25 \mathrm{mV} \mathrm{s}^{-1}$ ) of CNT ink in presence and absence of $1.0 \mathrm{mmol}^{-1} \mathrm{~K}_{3}\left[\mathrm{Fe}(\mathrm{CN})_{6}\right]$ recorded in $0.1 \mathrm{~mol} \mathrm{~L}^{-1} \mathrm{PBS}, \mathrm{pH}=7$

\section{CNT ink optimization}

The proportion of modifiers in CNT ink can significantly affect its electrical performance. Therefore, it is important to optimize a value where the f-CNT and SDS concentrations result in better dispersion and good conductivity. The ultraviolet-visible (UV-Vis) spectroscopy was used to evaluate this. This technique is used to obtain the absorbance spectra of a compound in solution. In this work, the purpose is to study the dispersing effect of the concentration of $\mathrm{f}$-CNT and SDS and to determine the optimal initial amount of carbon nanotubes in the solution. Figure 13 shows the UV-visible spectra for different concentrations of CNT (a) and SDS (b).

As observed in the spectra, the absorption of CNT ink appeared at $252 \mathrm{~nm}$. The previous literature data concerning the absorbance of carbon nanotubes dispersion relate this absorption to different transitions. Rance et al. [88] and Zeinabad et al. [89] associate that band to the plasmon resonances in the free electron of the nanotubes $\pi$ electrons. To put it another way, the band is imputable to $\pi-\pi^{*}$ transitions due to electrons of the double bonds in the CNT. However, Jiang et al. [90] and Yadav et al. [91] related the band to the transition due to an unshared pair of electrons of the $-\mathrm{C}=\mathrm{O}$ bond in the carboxylic groups (- $\mathrm{COOH}$ ) on the CNT surface.

The spectra presented in Figure 13(a) show that increasing the concentration of $\mathrm{f}$-CNT results in an increasing absorbance intensity. When the concentration is $10 \mathrm{mg} \mathrm{mL}^{-1}$, the absorption is the highest. A higher quantity of $\mathrm{f}-\mathrm{CNT}$ in the dispersion can enhance the dispersing effect. However, 
there is a limit when the concentration of $\mathrm{f}$-CNT reaches a certain degree that the dispersion effect is reduced. That is observed since the concentration difference between the absorbance at 8 and $10 \mathrm{mg} \mathrm{mL}^{-1}$ is minimum [91].
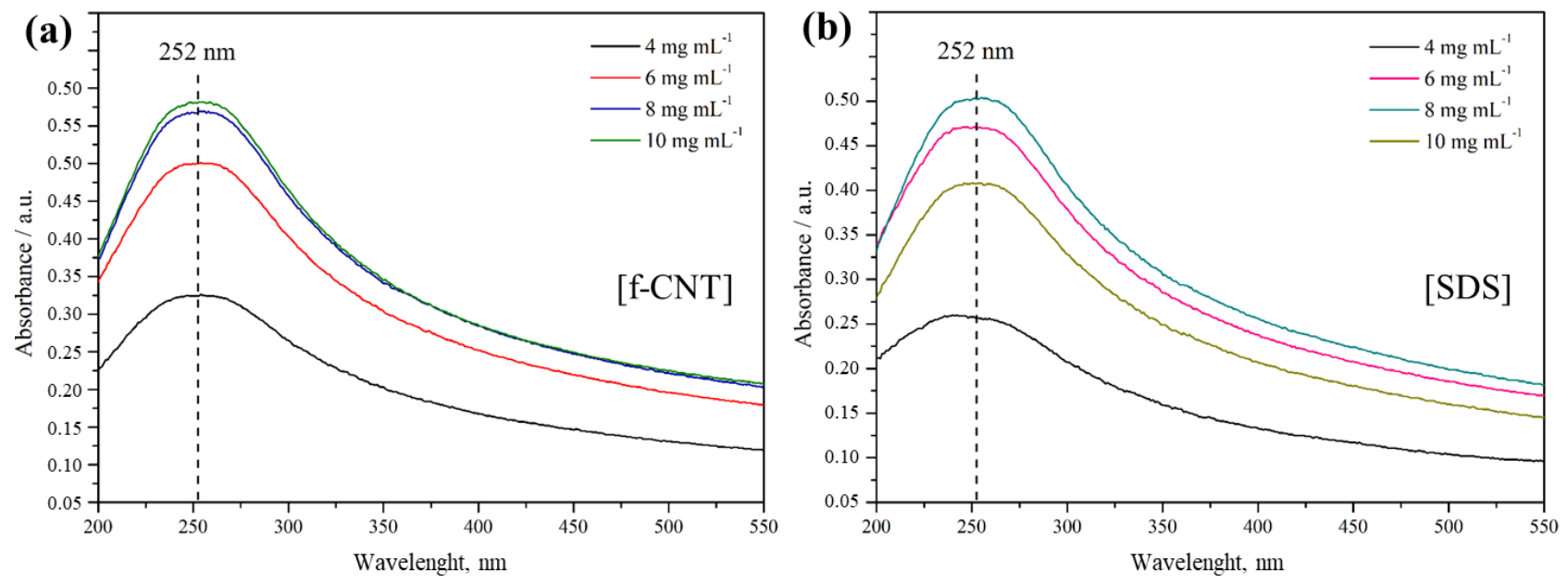

Figure 13. UV-Vis spectra for CNT ink as a function of: (a) $f$-CNT concentration and (b) SDS concentration. The solutions are diluted by a factor of 10 when taking UV-Vis measurements

As seen in Figure 13(b), the highest absorbance is obtained for the SDS concentration of $8 \mathrm{mg} \mathrm{mL}^{-}$ ${ }^{1}$ due to the higher $\mathrm{f}$-CNT concentration in dispersion. After that, the absorbance decreases. At lower SDS concentrations, there is not enough SDS to coat the f-CNT surface to prevent agglomeration. On the other hand, higher SDS concentrations can harm the dispersion since there is a limit of f-CNT that can be dispersed. After that, the exceeds of SDS will only decrease the conductivity of the ink [91]. This behavior is demonstrated using the cyclic voltammogram and ohmic resistance.

To evaluate the electrochemical behavior of the CNT ink in different concentrations, several working electrodes were fabricated using different inks. Figure 14(a) show the electrodes made with different concentration of $\mathrm{f}$-CNT. The resulting ohmic resistance is presented in Figure 14(b). As noticed, at $8 \mathrm{mg} \mathrm{mL}^{-1}$ the ohmic resistance reaches the minimum value, resulting in more conductive ink. That behavior is also observed in Figure 14(c) and Figure 14(d), when the electrode was used in a three-electrode cell in the presence and absence of an electrochemical probe.

The optimal concentration of $\mathrm{f}-\mathrm{CNT}$ is $8 \mathrm{mg} \mathrm{mL}^{-1}$. At this concentration, the electrochemical behavior exhibited the best voltammetric profile and highest peak current variation. Although UVVis experiments show higher $\mathrm{f}$-CNT dispersion in $10 \mathrm{mg} \mathrm{mL}^{-1}$, the electrochemical behavior and ohmic resistance proved that the CNT ink conductivity is higher at $10 \mathrm{mg} \mathrm{mL}^{-1}[91,92]$. Therefore, the chosen $\mathrm{f}$-CNT concentration in the CNT ink was $8 \mathrm{mg} \mathrm{mL}^{-1}$.

Concerning the SDS concentration, Figure 15(a) presents the electrodes constructed using different SDS concentrations. The ohmic resistance of each electrode was measured and the results are presented in Figure 15(b). The SDS concentration at $8 \mathrm{mg} \mathrm{mL}^{-1}$ has the lowest ohmic resistance. That result is in agreement with the electrochemical behavior in Figures 15(c) and Figure 15(d). At $8 \mathrm{mg} \mathrm{mL}^{-1}$, the peak current variation is the highest, proving the best ink conductivity at this concentration $[92,93]$.

In summary, the optimized composition of carbon nanotube was $8 \mathrm{mg} \mathrm{mL}^{-1}$ of $\mathrm{f}$-CNT and $8 \mathrm{mg} \mathrm{mL}^{-1}$ of SDS. The concentration optimization is significant to find the ideal condition for printing. The conductive ink with the greatest possible electrical properties can be used to fabricate circuits, electrochemical sensors, for screen-printing and other applications. 
(a)

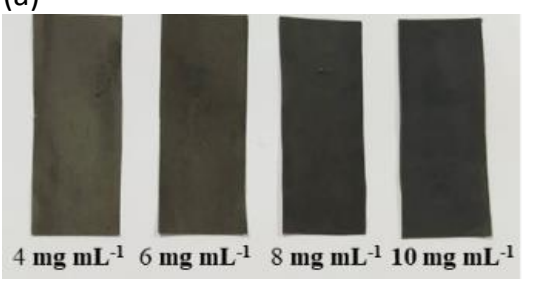

(b)

\begin{tabular}{|c|c|c|c|c|}
\hline & 4 & 6 & 8 & 10 \\
\hline & \multicolumn{4}{|c|}{ Ohmic resistance, $\mathrm{k} \Omega$} \\
\hline Measurement 1 & 49.26 & 36.43 & 18.68 & 21.26 \\
\hline Measurement 2 & 49.23 & 36.52 & 18.62 & 21.36 \\
\hline Measurement 3 & 49.15 & 36.38 & 18.55 & 21.37 \\
\hline Average \pm SD & $49.21 \pm 0.05$ & $36.44 \pm 0.06$ & $19.62 \pm 0.05$ & $21.36 \pm 0.08$ \\
\hline
\end{tabular}
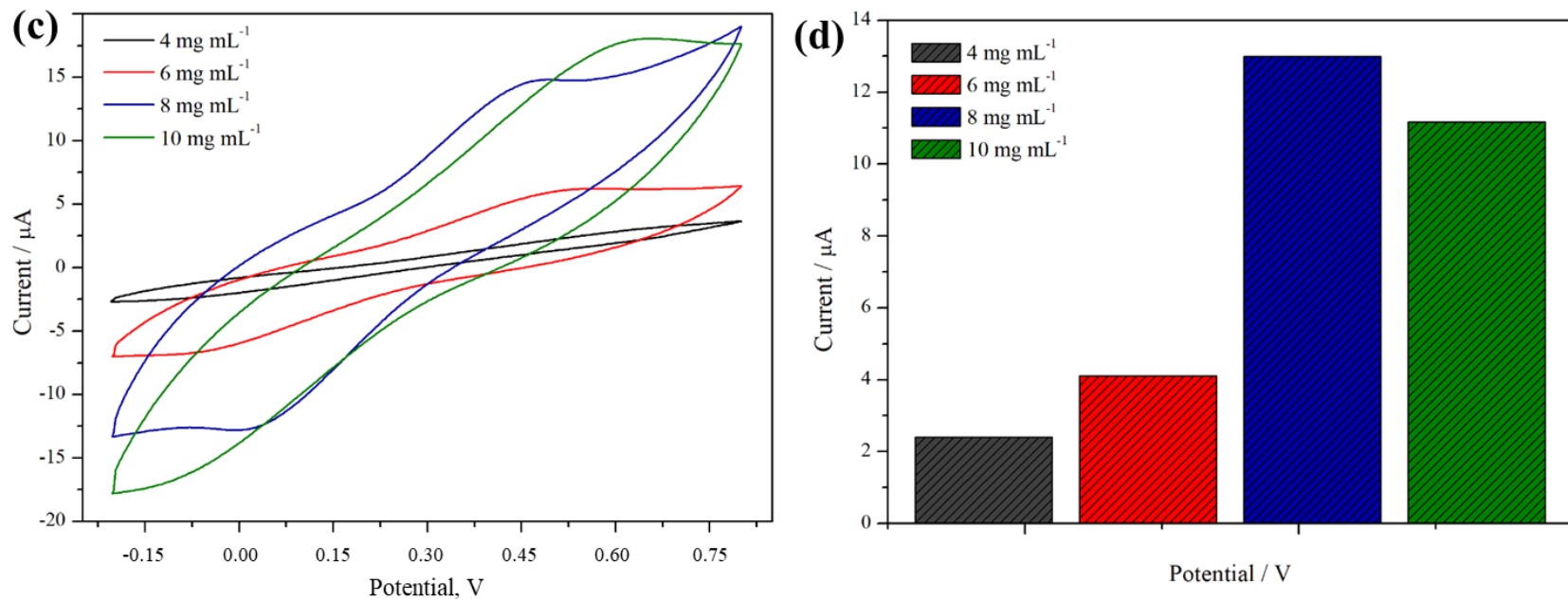

Potential / V

Figure 14. (a) Electrodes fabricated with different concentrations of $f$-CNT; (b) ohmic resistance values; (c) CVs (scan rate $=25 \mathrm{mV} \mathrm{s}^{-1}$ ) of CNT ink with different concentrations of $f$-CNT with 1.0 $\mathrm{mmol} \mathrm{L}^{-1} \mathrm{~K}_{3}\left[\mathrm{Fe}(\mathrm{CN})_{6}\right]$ recorded in $0.1 \mathrm{~mol} \mathrm{~L}^{-1} \mathrm{PBS} \mathrm{pH}=7$; (d) peak current intensities

(a)

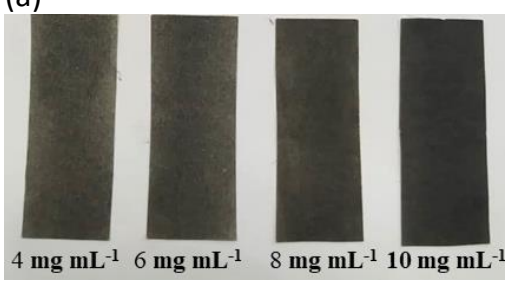

(b)

\begin{tabular}{cccc}
\multicolumn{4}{c}{$C_{\text {SDS }} / \mathrm{mg} \mathrm{ml}^{-1}$} \\
\hline 4 & 6 & 8 & 10 \\
\hline \multicolumn{4}{c}{ Ohmic resistance, $\mathrm{k} \Omega$} \\
\hline 34.03 & 22.61 & 18.68 & 25.31 \\
\hline 34.97 & 22.55 & 18.62 & 25.37 \\
\hline $34.03 \pm 0.05$ & $22.58 \pm 0.03$ & 18.55 & 25.43 \\
\hline
\end{tabular}

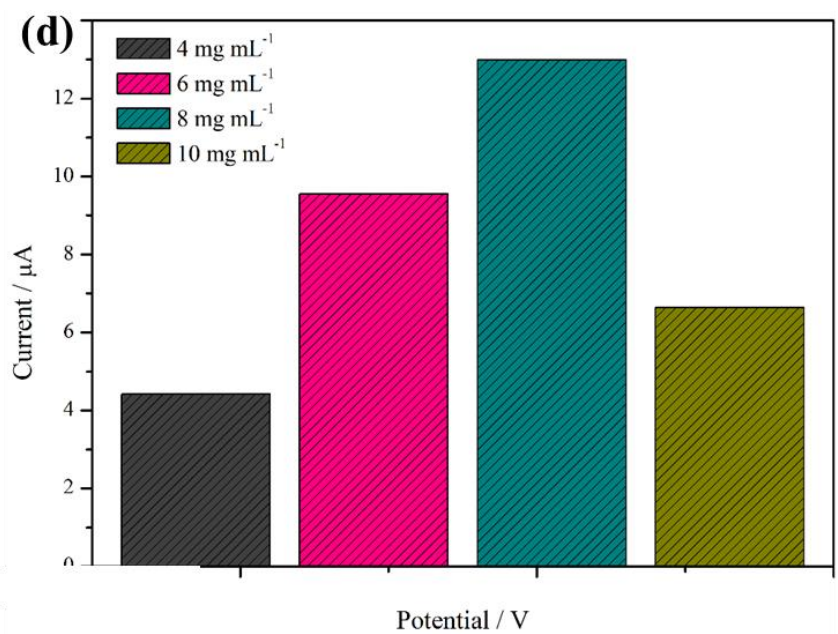

Potential / V

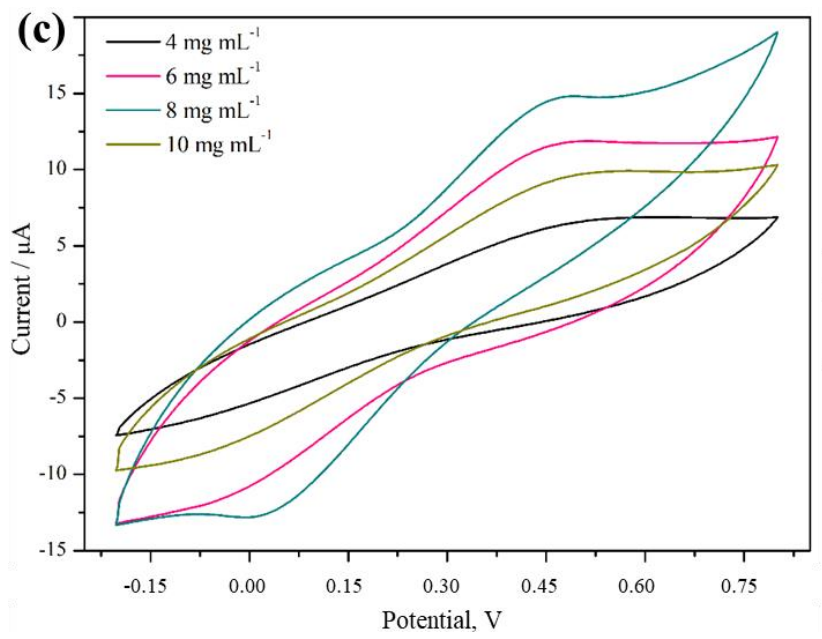

Figure 15. (a) Electrodes fabricated with different concentrations of SDS; (b) ohmic resistance values; (c) CVs (scan rate $=25 \mathrm{mV} \mathrm{s}^{-1}$ ) of CNT ink with different concentrations of SDS with 1.0 mmol $L^{-1} K_{3}\left[\mathrm{Fe}(\mathrm{CN})_{6}\right]$ recorded in $0.1 \mathrm{~mol} \mathrm{~L}^{-1} \mathrm{PBS}(\mathrm{pH} 7)$; (d) peak current intensities

\section{Comparision with previous works}

Some examples of CNT inks taken from already published papers are presented in Table 1 . The most used surfactant in the fabrication of CNT ink is SDS. Costa et al., Chen et al. and Tortorich et al. 
synthesized CNT ink using only SDS in deionized water [10-12]. Although other researchers have already proposed routes for CNT ink using SDS, most of them did not address the stability issue and how the use of only SDS may result in CNT ink with low stability. That is why some authors are using more than one modifier in the fabrication of CNT inks, besides SDS. For example, Menon et al. [12] fabricated a MWCNT ink using ethanol, SDS and PVP, while Matsuzawa et al. [13] used SWCNT with SDS, sodium chlorate (SOC) and deoxy chlorate (DOC).

Table 1. Review of CNT inks synthesized in the past decade and their electrical properties

\begin{tabular}{ccccc}
\hline Conductor & Functionalization & Additives & Solvent & Reference \\
\hline SWCNT & Non-Covalent & SDBS & Water & {$[3]$} \\
\hline MWCNT & Non-Covalent & PVP & Water & {$[4]$} \\
\hline MWCNT & Non-Covalent & $\mathrm{SCMC}$ & Water & {$[5]$} \\
\hline MWCNT & Covalent & $\mathrm{HNO}_{3} / \mathrm{H}_{2} \mathrm{SO}_{4}$ & Water & {$[6]$} \\
\hline MWCNT & Non-Covalent & Chitosan/Acetic Acid & Water & {$[7]$} \\
\hline SWCNT & Non-Covalent & TX100/CMC/PAA & Water & {$[8]$} \\
\hline SWCNT & Non-Covalent & $\mathrm{SDS}$ & Water & {$[9]$} \\
\hline SWCNT & Non-Covalent & $\mathrm{SDS}$ & Water & {$[10]$} \\
\hline SWCNT & Non-Covalent & $\mathrm{SDS}$ & Water & {$[11]$} \\
\hline MWCNT & Non-Covalent & SDS/PVP & Ethanol & {$[12]$} \\
\hline SWCNT & Non-Covalent & $\mathrm{SDS} / \mathrm{SOC} / \mathrm{DOC}_{3}$ & Water & {$[13]$} \\
\hline MWCNT & Covalent and Non-Covalent & $\mathrm{HNO}_{3} / \mathrm{H}_{2} \mathrm{SO}_{4}$ and SDS & Water & This work \\
\hline
\end{tabular}

SWCNT: Single-wall carbon nanotube; MWCNT: multi-wall carbon nanotube; SDBS: sodium dodecylbenezenesulfonate; PVP: polyvinylpyrrolidone; SCMC: sodium carboxymethyl cellulose; TX100: triton X-100; CMC: carboxymethylcellulose; PPA: polyacrylic acid; SDS: sodium dodecyl sulfate; SOC: sodium chlorate; DOC: deoxy chlorate

\section{Conclusions}

In this work, a CNT ink was fabricated using both covalent and non-covalent functionalizations. The covalent functionalization was performed in the acid medium using $\mathrm{H}_{2} \mathrm{SO}_{4}$ and $\mathrm{HNO}_{3}$. The noncovalent used SDS and ultrasonication. The combination of inserted functional groups and the absorption of SDS hydrophobic tail in the CTN surface resulted in a well-dispersed ink with excellent storage stability over several months.

The electrode modifier materials (SDS, CNT, CNT/SDS, f-CNT and f-CNT/SDS) were characterized by FTIR, SEM, electrochemical measurements and EIS. FTIR results indicated that in the non-covalent functionalization, the SDS was successfully adsorbed on the f-CNT surface, while in the covalent functionalization, the functional groups $(-\mathrm{COOH}, \mathrm{C}=\mathrm{O}$ and $-\mathrm{OH})$ were inserted in the CNT surface.

The SEM images show that the SDS keeps the CNTS apart, preventing their entanglement and agglomeration. Meanwhile, the covalent functionalization resulted in a rougher surface structure due to the attachment of oxygenated functional groups.

Electrochemical measurements including EIS indicate that SDS and the presence of functional groups facilitate electron transfer by improving electrical conductivity. The electrical properties were investigated and the CNT ink showed a good conductivity, with an average resistance of CNT ink is $18.62 \mathrm{k} \Omega$. The CNT ink was used to fabricate a working electrode and the electrochemical behaviour was evaluated. The behaviour showed the peaks corresponding to the redox couple $\left[\mathrm{Fe}(\mathrm{CN})_{6}\right]^{4-} /\left[\mathrm{Fe}(\mathrm{CN})_{6}\right]^{3-}$ with a small resistive profile and low background current.

The CNT ink fabricated remained stable over several months. Even though other researchers have already proposed routes for CNT ink using SDS, most of them do not address the stability issue and how the use of only SDS may result in CNT ink with low stability. 
In summary, the CNT ink fabricated is conductive, with good dispersion and excellent stability. Therefore, it can be used in several areas, including the goal of this work, the fabrication of electrochemical sensors.

Acknowledgement: We thank UFSJ, FAPEMIG, CAPES, CNPQ and Rede Mineira de Química for the continuous support of our research.

\section{References}

[1] S. Iijima, Nature 354 (1991) 56-58. https://doi.org/10.1038/354056a0

[2] S. Mallakpour, S. Soltanian, RSC Advances 111 (2016) 109916-109935. https://doi.org/ 10.1039/C6RA24522F

[3] K. H. Maria, T. Mieno, Carbon Nanotubes - Recent Progress, IntechOpen, London, United Kingdom, 2018, pp. 235-261. ISBN 9781789230529

[4] J. Han, B. Kim, J. Li, M. Meyyappan, Materials Research Bulletin 50 (2014) 249-253. https://dx.doi.org/10.1016/i.materresbull.2013.10.048

[5] O. Garate, L. Veiga, A. V. Medrano, G. Longinotti, G. Ybarra, L. N. Monsalve, Materials Research Bulletin 106 (2018) 137-143. https://dx.doi.org/10.1016/i.materresbull.2018. $\underline{05.015}$

[6] A. Aziz, M. B. Bazbouz, M. E. Welland, ACS Applied Nano Materials 3 (2020) 9385-9392. https://doi.org/10.1021/acsanm.0c02013

[7] L. Ziyin, T. Le, X. Song, Y. Yao, Z. Li, K. Moon, M. Tentzeris, C. P. Wong, Journal of Electronic Packaging 135 (2013) 011001-5. https://doi.org/10.1115/1.4023758

[8] B. Dinesh, R. Saraswathi, A. Senthil Kumar, Electrochimica Acta 233 (2017) 92-104. https://doi.org/10.1016/i.electacta.2017.02.139

[9] Y. Wang, H.-J. Yang, H.-Z. Geng, Z.-C. Zhang, E.-X. Ding, Y. Meng, Z.-J. Luo, J. Wang, X.-M. Su, S.-X. Da, Journal of Materials Chemistry C 15 (2015) 3796-3802.

https://doi.org/10.1039/C5TC00138B

[10] T. H. Costa, E. Song, R. P. Tortorich, J-W. Woo, ECS Journal of Solid State Science and Technology 4 (2015) S3044. https://doi.org/10.1149/2.0121510jss

[11] P. Chen, H. Chen, J. Qiu, C. Zhou, Nano Research 8 (2010) 594-603. https://doi.org/ 10.1007/s12274-010-0020-x

[12] R. P. Tortorich, E. Song, J.-W. Choi, Journal of The Electrochemical Society 161 (2013) B3044-B3048. https://doi.org/10.1149/2.0121510jss

[13] H. Menon, R. Aiswarya, K. P. Surendran, RSC Advances 7 (2017) 44076-44081. https://doi.org/10.1039/C7RA06260E

[14] Y. Matsuzawa, H. Jintoku, Chemistry Letters 48 (2019) 674-677. https://doi.org/10.1246/ cl.190161

[15] G. Tobias, E. Mendoza, B. Ballesteros, Encyclopedia of Nanotechnology, Springer, Columbus, USA, 2012, pp 911-919. ISBN 978-90-481-9752-1

[16] L. Y. Jun, N. M. Mubarak, M. J. Yee, L. S. Yon, C. H. Bing, M. Khalid, E. C. Abdullah, Journal of Industrial and Engineering Chemistry, 67 (2018), 175-186. https://doi.org/10.1016/ j.jiec.2018.06.028

[17] M. Karimi, N. Solati, M. Amiri, H. Mirshekari, E. Mohamed, M. Taheri, M. Hashemkhani, A. Saeidi, M. A. Estiar, P. Kiani, A. Ghasemi, S. M. Basri, A. R. Aref, M. R. Hamblin, Expert opinion on drug delivery 12 (2015) 1071-1087. https://doi.org/10.1517/17425247.2015.10 $\underline{03806}$

[18] A. G. Osorio, I. C. L. Silveira, C. P. Bergmann, Applied Surface Science 255 (2008) 2485-2489. https://doi.org/10.1016/i.apsusc.2008.07.144 
[19] T. T. Nguyen, S. U. Nguyen, D. T. Phuong, D. C. Nguyen, A. T. Mai, Adv. Nat. Sci.: Nanosci. Nanotechnol. 2 (2011) 1-4. https://doi.org/10.1088/2043-6262/2/3/035015

[20] L. T. M. Hoa, Diamond and Related Materials 89 (2018) 43-51. https://doi.org/10.1016/ j.diamond.2018.08.008

[21] A. L. Pistone, A. Ferlazzo, M. Lanza, C. Milone, D. Iannazzo, A. Piperno, E. Piperopoulos, S. J. Galvagno, Nanosci Nanotechnol. 12 (2012) 5054-60. https://doi.org/10.1166/inn.2012. 4928

[22] B. Ribeiro, E. C. Botelho, M. L. Costa, C. F. Bandeira, Polímeros 27 (2017) 247-255. https://doi.org/10.1590/0104-1428.03916

[23] R. P. Tortorich, H. Shamkhalichenar, J. Choi, Appl. Sci. 2 (2018) 1-16. https://doi.org/10.33 90/app8020288

[24] C. Klumpp, K. Kostarelos, M. Prato, A. Bianco, Biochimica et Biophysica Acta (BBA) Biomembranes 1758 (2006) 404-412. https://doi.org/10.1016/j.bbamem.2005.10.008

[25] I. Jeon, D. W. Chang, N. A. Kumar, J. Baek, Polymer Nanocomposites - Siva Yellampalli, IntechOpen, London, United Kingdom, 2011, pp 396-343. https://doi.org/10.5772/18396

[26] W. H. Duan, Q. Wang, F. Collins, Chem. Sci. 2 (2011) 1407-1413. https://doi.org/10.1039/ COSC00616E

[27] K. Yang, Z. L. Yi, Q. F. Jing, R. L. Yue, W. Jiang, D. H. Lin, Materials Science 58 (2013) 20822090. https://doi.org/10.1007/s11434-013-5697-2

[28] O. Matarredona, H. Rhoads, Z. Li, J. H. Harwell, L. Balzano, D. E. Resasco, J Phys Chem B 107 (2003) 13357-13367. https://doi.org/10.1021/jp0365099

[29] J. Yu, N. Grossiord, C. E. Koning, L. Joachim, Carbon 45 (2007) 618-623. https://doi.org/ 10.1016/i.carbon.2006.10.010

[30] J. E. L. Siqueira, P. J. P. Gleize, Rev. IBRACON Estrut. Mater. 13 (2020) 455-463. https://doi.org/10.1590/S1983-41952020000200013

[31] J. W. Su, C. Y. Hsu, S. J. Fu, C. H. Guo, K. J. Lin, J. Chin. Chem. Soc. 56 (2009) 935-939. https://doi.org/10.5772/16526

[32] R. S. Sahota, S. M. Dakka, ChemEngineering 36 (2020) 1-19. https://doi.org/10.3390/ chemengineering4020036

[33] J. B. Russel, Química Geral 2ª edição, Pearson, São Paulo, São Paulo, 1994, pp 20-50. ISBN 9788534601511

[34] J. Clayden, N. Greeves, S. Warren, Organic Chemistry 2 ${ }^{a}$ edição, Oxford University Press, Oxford, United Kingdom, 2012, pp. 10-90. ISBN: 978-0199270293

[35] W. Martindale, The Extra Pharmacopeia, 29th ed., The Pharmaceutical Press, London, United Kingdom, 1989, pp. 12-50. ISBN 0853693005

[36] A. M. Grumezescu, Fullerenes, Graphenes and Nanotubes: A Pharmaceutical Approach, Elsevier, Oxford, United Kingdom, 2018, pp 11-50. ISBN 9780128136928

[37] A. Almowarai, Y. Ueno, Y. Show, Journal of Nanomaterials 315017 (2015) 1-7. https://doi.org/10.1155/2015/315017

[38] M. Meyyappan, Carbon Nanotubes Science and Applications, CRC Press, Boca Raton, USA, 2004, pp 11-25. ISBN 9780849321115

[39] S. Manzetti, J. Gabriel, International Nano Letters 9 (2019) 31-49. https://doi.org/10.1007/ s40089-018-0260-4

[40] B. Qiao, Y. Liang, T.-J. Wang, Y. Jiang, Applied Surface Science 364 (2016) 103-109. https://doi.org/10.1016/j.apsusc.2015.12.116

[41] H. Lun, J. Ouyang, H. Yang, Phys Chem Minerals 41 (2014) 281-288. https://doi.org/ 10.1007/s00269-013-0646-9

[42] M. Choudhary, S. M. Kamil, ACS Omega 5 (2020) 22891-22900. https://doi.org/10.1021/ acsomega.0c02255 
[43] M. S. Muhamad, M. R. Salim, W. Lauc, RSC Adv. 5 (2015) 58644-58654. https://doi.org/ 10.1039/C5RA07527K

[44] R. B. Viana, A. B. F. Silva, A. Pimentel, Advances in Physical Chemistry 9 (2012) 1-14. https://doi.org/10.1155/2012/903272

[45] M. A. E. Hafizah, A. F. Riyadi, A. Mana, A. Andreas, Materials Science and Engineering 515 (2019) 012080. https://doi.org/10.1088/1757-899X/515/1/012080

[46] S. A. Wulandaril, H. Widiyandari, A. Subagi, J. Phys.: Conf. Ser. 1025 (2018) 012005-012015. https://doi.org/10.1088/1742-6596/1025/1/012005

[47] M. A. Nawas, S. Rauf, G. Catanante, M. H. Nawaz, G. Nunes, J. L. Marty, Sensors 16 (2016) 1651-1665. https://doi.org/10.3390/s16101651

[48] A. TermehYousefi, S. Bagheri, K. Shinji, J. Rouhi, M. Rusop, S. Ikedal, BioMed Research International 691537 (2014) 1-6. https://doi.org/10.1155/2014/691537

[49] J. M. Domínguez-González, P. Castell, S. Bespín-Gaszón, A. Ansón-Casaos, A. M. DiézPascual, M. A. Gómez-Fatou, A. M. Banito, W. K. Maser, M. T. Martinéz, J. Mater. Chem. 22 (2012) 21285-21297. https://doi.org/10.1039/c2jm35272a

[50] J. Wei, M. Saharudin, T. Vo, F. Inam, J Reinf Plast Comp 37 (2018) 1-8. https://doi.org/ 10.1177/0731684418765369

[51] P. Cañete-Rosales, A. Álvarez-Lueje, S. Bollo, Sensors and Actuators B: Chemical 191 (2014) 688-694. https://doi.org/10.1016/i.snb.2013.10.056

[52] B. R. C. Menezes, F. V. Ferreira, B. C. Silva, E. A. N. Simonetti, T. M. Bastos, L. S. Cividanes, G. P. Thim, Journal of Materials Science 53 (2018) 14311-14327. https://doi.org/10.1007/s10853-018-2627-3

[53] G. Mago, C. Velasco-Santos, A. L. Martinez-Hernandez, D. M. Kalyon, F. T. Fisher, MRS Proceedings 1056 (2007) 1-6. https://doi.org/10.1557/PROC-1056-HH11-35

[54] J. M. Domínguez-González, P. Castell, S. Bespín-Gaszón, A. Ansón-Casaos, A. M. DiézPascual, M. A. Gómez-Fatou, A. M. Banito, W. K. Maser, M. T. Martinéz, J. Mater. Chem. 22 (2012) 21285-21297. https://doi.org/10.1039/c2jm35272a

[55] J. Navamani, R. Palanisamy, R. Gurusamy, M. Ramasamy, S. J. Arumugam, Biosens Bioelectron 3 (2012) 1-14. https://doi.org/10.4172/2155-6210.1000122

[56] R. Yudianti, H. Onggo, Y. Surdirman; Y. Saito, T. Iwata, J. Azuma, The Open Materials Science Journal 5 (2011) 242-247. https://doi.org/10.2174/1874088X01105010242

[57] J. Wei, M. Saharudin, T. Vo, F. Inam, J Reinf Plast Comp 37 (2018) 1-8. https://doi.org/ $10.1177 / 0731684418765369$

[58] P. Zhang, G. Qian, Z. P. Xu, H. Shi, X. Ruan, J. Yang, R. L. Frost, Journal of Colloid and Interface Science 367 (2012) 264-271. https://doi.org/10.1016/i.jcis.2011.10.036

[59] H.-T. Chan, R. Bhat, A. A. Karim, Food Chemistry 120 (2010) 703-709. https://doi.org/ 10.1016/i.foodchem.2009.10.066

[60] M. Marvi, N. Farsaeivahid, M. Jamal, S. M. Naghib, A. Ghaffarinejad, Conference Paper 5772 (2018) 1-11. https://doi.org/10.3390/ecsoc-22-05772

[61] Y. J. Lau, J. L. S. Yon, Y. Shang, M. Mujawar, M. Khalid, C. Bing, IOP Conference Series: Materials Science and Engineering 495 (2019) 012057. https://doi.org/10.1088/1757899X/495/1/012057

[62] E. Malikov, M. Muradov, O. Akperov, G. Eyvazova, R. Puskas, D. Madarász, L. Nagy, A. Kukovecz, Z. Kónya, Physica E: Low-dimensional Systems and Nanostructures 61 (2014) 129134. https://doi.org/10.1016/j.physe.2014.03.026

[63] W. Li, W.-M. Ji, Y. Liu, F. Xing, Y.-K. Liu, Journal of Nanomaterials 371404 (2015) 1-7. https://doi.org/10.1155/2015/371404

[64] S. Chatterjee, F. Nüesch, B. T. -T. Chu, Nanotechnology 22 (2011) 275714. https://doi.org/10.1088/0957-4484/22/27/275714 
[65] D. Ramimoghadam, M. Z. B. Hussein, Y. H. Taufiq-Yap, Int. J. Mol. Sci. 13 (2012) 1327513293. https://doi.org/10.3390/ijms131013275

[66] D. G. Dalgleish, P. A. Spagnuolo, H. D. Goff, International Dairy Journal, 14 (2004) 10251031. https://doi.org/10.1016/i.idairyj.2004.04.008

[67] L. R. Rasteiro, L. H. Vieira, C. V. Santilli, L. Martins, RSC Adv. 8 (2018) 11975-11982. https://doi.org/10.1039/C8RA01443D

[68] B. Kumar, B. K. Kaushik, Journal of Materials Science: Materials in Electronics 25 (2014) 130. https://doi.org/10.1007/s10854-013-1550-2

[69] Y. Wang, G. J. Weng, Micromechanics and Nanomechanics of Composite Solids, Springer International Publishing, 2017, pp 123-156. ISBN 978-3-319-52794-9

[70] C. Raril, J. G. Manjunatha, Biomed J Sci \& Tech Res 11 (2018) 8560-8564. https://doi.org/ 10.26717/BJSTR.2018.11.002108

[71] F. Chekin, J. B. Raoof, S. Bagheri, S. B. A. Hamid, Analytical Methods 4 (2012) 2977-2981. https://doi.org/10.1039/C2AY25427A

[72] W. Zhang, J. Chen, G. F. Swiegers, Z.-F. Ma, G. G. Wallace, Nanoscale 2 (2010) 282-286. https://doi.org/10.1039/B9NR00140A

[73] Y. Wu, Y. Zhang, Y. Liu, P. Cui, S. Chen, Z. Zhang, J. Fu, E. Xie, ACS Applied Materials \& Interfaces 12 (2020) 42933-42941. https://doi.org/10.1021/acsami.0c11085

[74] J. G. Roberts, L. Z. Lugo-Morales, P. L. Loziuk, L. A. Sombers, Methods in molecular biology, 2013, 964, 275-294. https://doi.org/10.1007/978-1-62703-251-3 16

[75] R. S. Hastak, P. Sivaraman, D. D. Potphode, K. Shashidhara, A. B. Samui, Journal of Solid State Electrochemistry 16 (2012) 3215-3226. https://doi.org/10.1007/s10008-012-1679-6

[76] M. Tang, J. Li, Z. Li, L. Fu, B. Zeng, J. Lv, Materials 12 (2019) 449-464. https://doi.org/ $\underline{10.3390 / \mathrm{ma} 12030449}$

[77] H. T. Jeong, J. F. Du, Y. R. Kim, Chemistry Select 21 (2017) 6057-6061. https://doi.org/ 10.1016/j.jiec.2017.10.009

[78] T. Yang, X. Ren, M. Yang, X. Li, K. He, A. Rao, Y. Wan, H. Yang, S. Wang, Z. Luo, Biosensors and Bioelectronics 141 (2019) 111406. https://doi.org/10.1016/j.bios.2019.111406

[79] R. A. Ahmed, R. A. Farghali, A. M. Fekry, International Journal of Electrochemical Science 7 (2012) 7270-7282. https://doi.org/10.5772/intechopen.74989

[80] L. Cao, Y. Wan, S. Yang, P. P. Jibin, Coatings 8 (2018) 285. https://doi.org/10.3390/coat ings 8080285

[81] H. Wu, K. Xi, S. Xiao, S. Ngai, C. Zhou, M. He, K. Shi, Y. Yu, Y. Yang, G. Chen, K. Ding, Surface and Coatings Technology 402 (2020) 126491.

https://doi.org/10.1016/i.surfcoat.2020.126491

[82] H.-C. Tian, J.-Q. Liu, X.-Y. Kang, D.-X. Wei, C. Zhang, J. C. Du, B. Yang, Y. Chen, C.-S. Yang, RSC Adv. 4 (2014) 47461. https://doi.org/10.1039/C4RA07265K

[83] C. Grisales, N. Herrera, F. Fajardo, Physics Education 51 (2016) 055011. https://doi.org/ 10.1088/0031-9120/51/5/055011

[84] R. P. Tortorich, H. Shamkhalichenar, J. Choi, Appl. Sci. 2 (2018) 1-16. https://doi.org/ 10.3390/app8020288

[85] C. Phillips, A. Al-Ahmadi, S.-J. Potts, T. Claypole, D. Deganello, Journal of Materials Science 52 (2017) 9520-9530. https://doi.org/10.1007/s10853-017-1114-6

[86] T. Zhong, N. Jin, W. Yuan, C. Zhou, W. Gu, Z. Cui, Materials (Basel) 8 (2019) 3036-3050. https://doi.org/10.3390/ma12183036

[87] D. A. C. Brownson, L. C. S. Figueiredo-Filho, B. L. Riehl, B. D. Riehl, M. Gómez-Mingot, J. Iniesta, O. Fatibello-Filho, G. E. Banks, J. Mater. Chem. A 4 (2016) 2617-2629.

https://doi.org/10.1039/C5TA08561F 
[88] G. A. Rance, D. H. Marsh, R. J. Nicholas, A. N. Khlobystov, Chemical Physics Letters 493 (2010) 19-23. https://doi.org/10.1016/i.cplett.2010.05.012

[89] H.A. Zeinabad, A. Zarrabian, A.A. Sboury, A. M. Alizadeh, M. Falahati, Scientific Reports 6 (2016) 26508. https://doi.org/10.1038/srep26508

[90] L. Jiang, L. Gao, J. Sun, Journal of Colloid and Interface Science 260 (2003) 89-94. https://doi.org/10.1016/S0021-9797(02)00176-5

[91] P. Yadav, R. Ajore, L. M. Bharadwaj, Journal of Nanotechnology Online 5 (2009) 2-14. https://doi.org/10.2240/azojono0130

[92] Y. Shi, L. Ren, D. Li, H. Gao, B. Yang, Journal of Surface Engineered Materials and Advanced Technology 3 (2013) 6-12. https://doi.org/10.4236/isemat.2013.31002

[93] K. Yang, Z. Yi, Q. Jing, R. Yue, W. Jiang, D. Lin, Chinese Science Bulletin 58 (2013) 2082-2090. https://doi.org/10.1007/s11434-013-5697-2

(C)2021 by the authors; licensee IAPC, Zagreb, Croatia. This article is an open-access article distributed under the terms and conditions of the Creative Commons Attribution license (https://creativecommons.org/licenses/by/4.0/) 